\title{
Prediction of the Density of Energetic Materials on the Basis of their Molecular Structures
}

\author{
Rahmatollah RAHIMI ${ }^{1}$, Mohammad Hossein KESHAVARZ ${ }^{2 *}$, \\ Ali Reza AKBARZADEH ${ }^{1}$
}

${ }^{1}$ Department of Chemistry, University of Science and Technology, P.O. Box: 16846-13114, Tehran, Islamic Republic of Iran

${ }^{2}$ Department of Chemistry,

Malek-ashtar University of Technology,

Shahin-shahr, P.O. Box 83145/115, Islamic Republic of Iran

*E-mail:mhkeshavarz@mut-es.ac.ir

\begin{abstract}
The density of an energetic compound is an essential parameter for the assessment of its performance. A simple method based on quantitative structureproperty relationship (QSPR) has been developed to give an accurate prediction of the crystal density of more than 170 polynitroarenes, polynitroheteroarenes, nitroaliphatics, nitrate esters and nitramines as important classes of energetic compounds, by suitable molecular descriptors. The evaluation techniques included cross-validation, validation through an external test set, and Y-randomization for multiple linear regression (MLR) and training state analysis for artificial neural network (ANN), and were used to illustrate the accuracy of the proposed models. The predicted MLR results are close to the experimental data for both the training and the test molecular sets, and for all of the molecular sets, but not as close as the ANN results. The ANN model was also used with 20 hidden neurons that gave good result. The results showed high quality for nonlinear modelling according to the squared regression coefficients for all of the training, validation and the test sets $\left(R^{2}=0.999,0.914\right.$ and 0.931 , respectively). The calculated results have also been compared with those from several of the best available predictive methods, and were found to give more reliable estimates.
\end{abstract}

Keywords: crystal density, energetic compound, QSPR, MLR, ANN 


\section{Introduction}

The condensed phase heat of formation and the crystal density of an energetic compound are two important parameters for an assessment of its performance [1]. Different performance computer codes, such as CHEETAH [2] and empirical methods [3-7], show a higher sensitivity of the predicted detonation performance to the crystal density than to the condensed phase heat of formation. Due to the importance of the prediction of performance, sensitivity, and physical and thermodynamic properties of a new energetic compound, the development of reliable estimation method scan reduce the cost and hazards effects of metastable high density energetic compounds.

Researchers have tried to generate an ability to predict, with satisfactory accuracy, the crystal densities of proposed new energetic compounds, for example by invoking atom/group volume additivities $[8,9]$ or by modelling the crystal structures $[10,11]$. Kim et al. have suggested that a prediction that differs by less than $0.03 \mathrm{~g} / \mathrm{cm}^{3}$ from the experimental value should be defined as 'excellent', while one that is between 0.03 and $0.05 \mathrm{~g} / \mathrm{cm}^{3}$ in error is still 'informative' [12]. For estimating the crystal density of available energetic materials, various methods have been developed. These include electrostatic potentials using quantum-mechanically determined molecular volumes [11-15], group additivities [8, 9, 16-18], empirical methods [19-22] and Quantitative Structure-Property Relationships (QSPR) [23].

It is preferable to search for a replacement for theoretical approaches so that the crystal density can be estimated directly from available molecular descriptors. Some procedures are available for the prediction of the crystal density of unknown compounds. One of these procedures involves computer-aided intensive calculations to predict possible crystal structures [24], from which densities can be readily computed. For a general model of $\mathrm{C}_{\mathrm{a}} \mathrm{H}_{\mathrm{b}} \mathrm{N}_{\mathrm{c}} \mathrm{O}_{\mathrm{d}}$ intermolecular interactions, the forceful simulation methodology QSPR of crystal prediction can be utilized. QSPR is an available method, which offers powerful tools for predicting different properties of chemicals. QSPR methods have been widely applied in the field of safety of energetic materials [25-30]. They have also been increasingly used for many years to determine physicochemical properties [31,32], especially of energetic materials [33-43]. QSPR is based on developing a mathematical relationship between a macroscopic property of a series of compounds and microscopic descriptors derived from their molecular structures, using an experimental data set. A model, once developed and validated, can be applied to predict the values of macroscopic properties of other materials with similar structures that have not been characterized yet and might not have even been synthesized. Furthermore, it could 
assist in a comprehension of investigated characteristics at the molecular scale. The purpose of the present work was to develop reliable QSPR procedures for estimating the crystal density of energetic compounds. It will be shown that an accurate prediction of the crystal density of important classes of energetic compounds, including polynitroarenes, polynitroheteroarenes, nitroaliphatics, nitrate esters and nitramines, can be acquired through suitable molecular descriptors.

\section{Method}

A critical point of any QSPR analysis is the choice of the experimental data set. Since experimental conditions can exert a strong influence on the crystal density, all of the experimental values used in the fitting procedure should be obtained under the same conditions, to ensure reliability and compatibility. The experimental densities of all of the molecules have been taken from different sources $[3,6,15,44-47]$. The molecular structures of these energetic compounds are given in Figure 1. Here, choice the training set is difficult, as the experimental conditions might significantly influence the measured explosive properties, i.e. the temperature (T) must be the same for all of the sets. The data set was randomly divided into two subsets for the MLR method: the training set contained 138 compounds ( $80 \%$ ) and the test set contained 34 compounds (20\%). We used the training set to build a regression model, and the test set to evaluate the predictive capability of the model developed. The 172 samples for the ANN method were randomly divided into 120 training samples (70\%), 26 testing samples (15\%) and 26 validation samples (15\%). The results of the methods are arranged in Table 1.

Table 1. The MSE and $\mathrm{R}^{2}$ values for the MLR and ANN results

\begin{tabular}{|c|c|c|c|c|}
\hline \multirow{2}{*}{ Method } & $\begin{array}{c}\text { Statistical } \\
\text { parameters }\end{array}$ & Training set & Testing set & Validation set \\
\hline \multirow{2}{*}{ MLR } & $\mathrm{R}^{2}$ & 0.899 & 0.886 & - \\
\cline { 2 - 5 } & $\mathrm{RMSE}$ & 0.089 & 0.098 & - \\
\hline \multirow{2}{*}{ ANN } & $\mathrm{R}^{2}$ & 0.999 & 0.931 & 0.971 \\
\cline { 2 - 5 } & $\mathrm{RMSE}$ & 0.009 & 0.079 & 0.052 \\
\hline
\end{tabular}


Figure 1. Molecular structures of 172 energetic compounds.

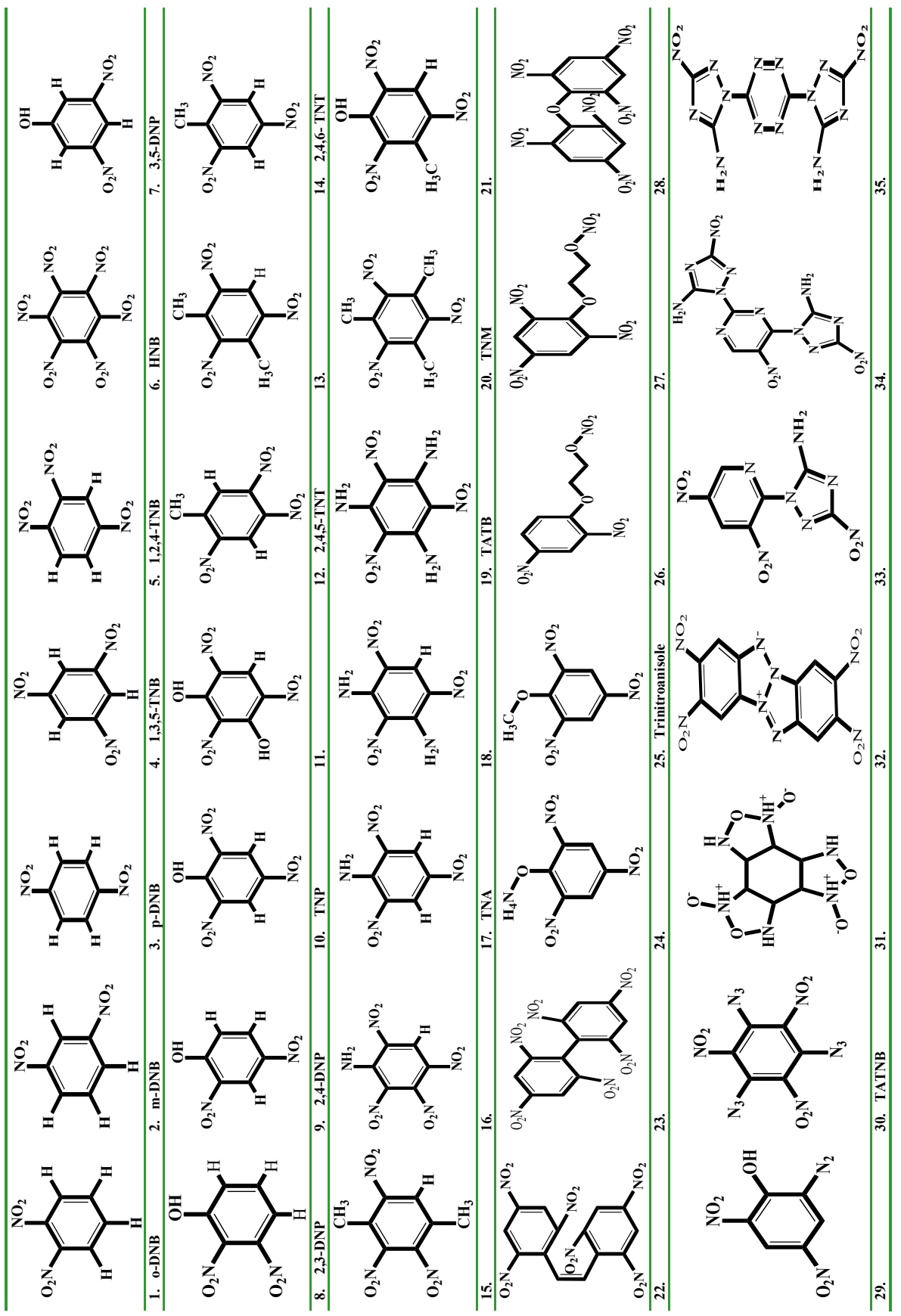


Figure 1. (Continued).

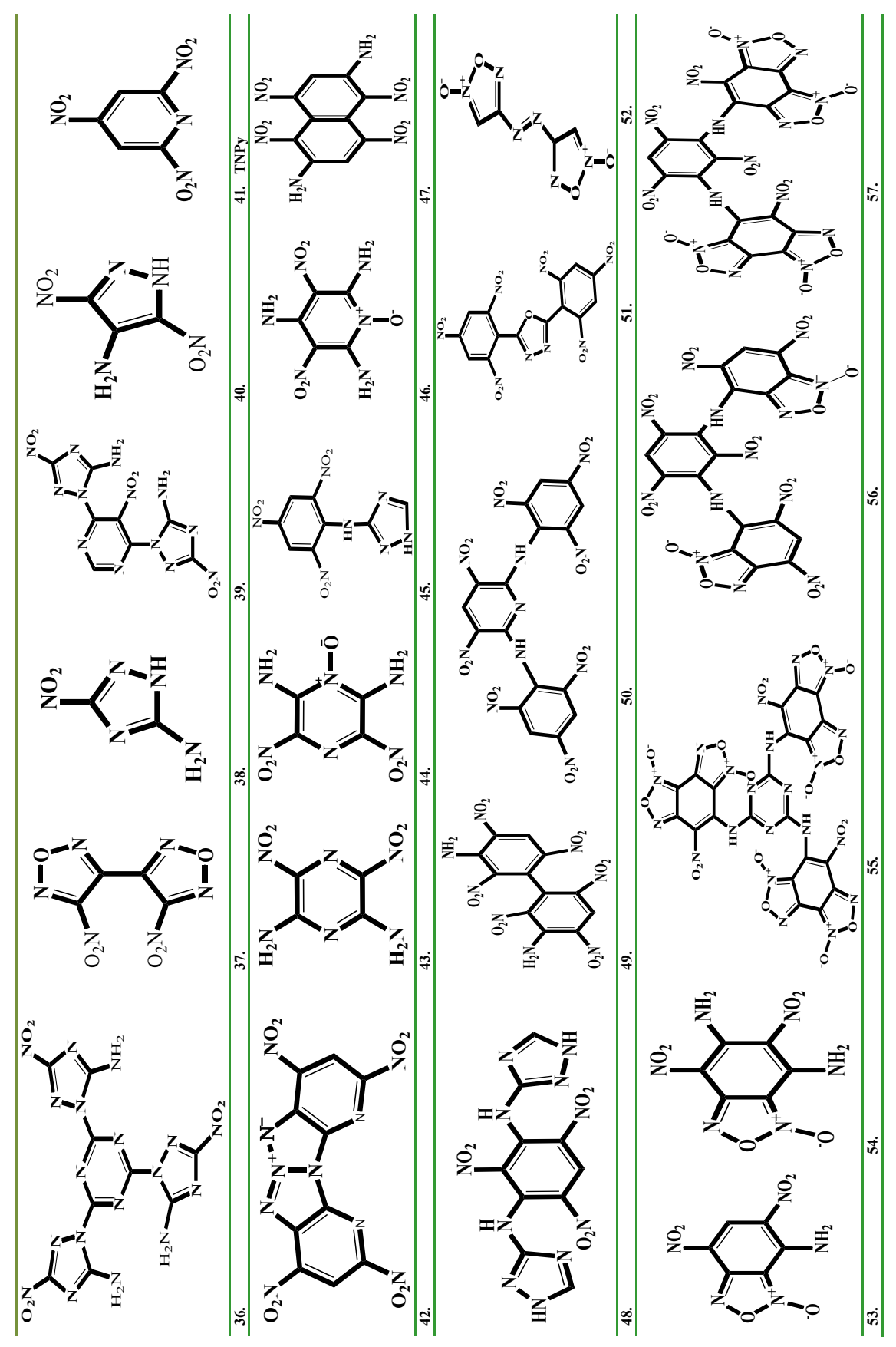


Figure 1. (Continued).

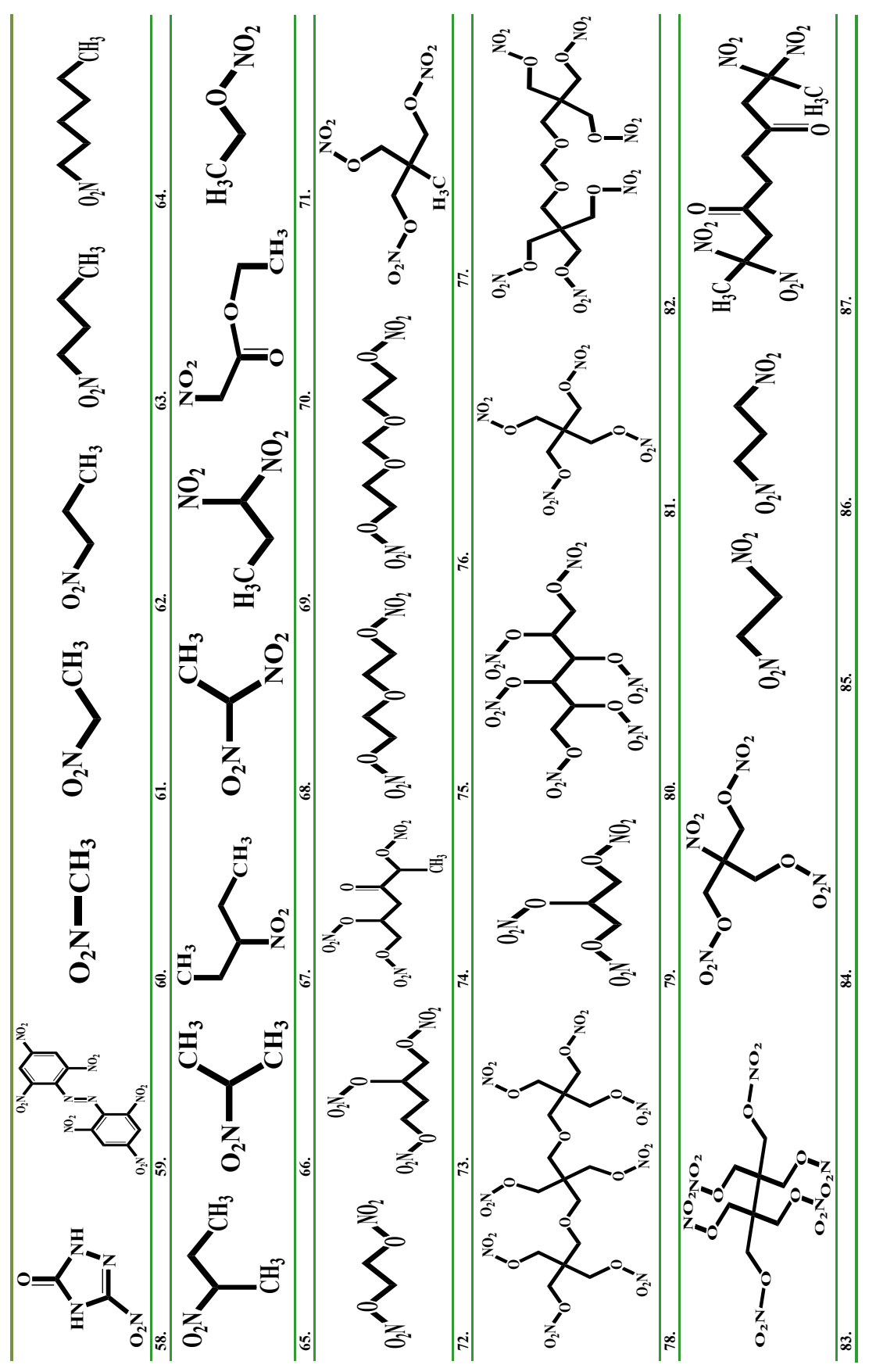


Figure 1. (Continued).

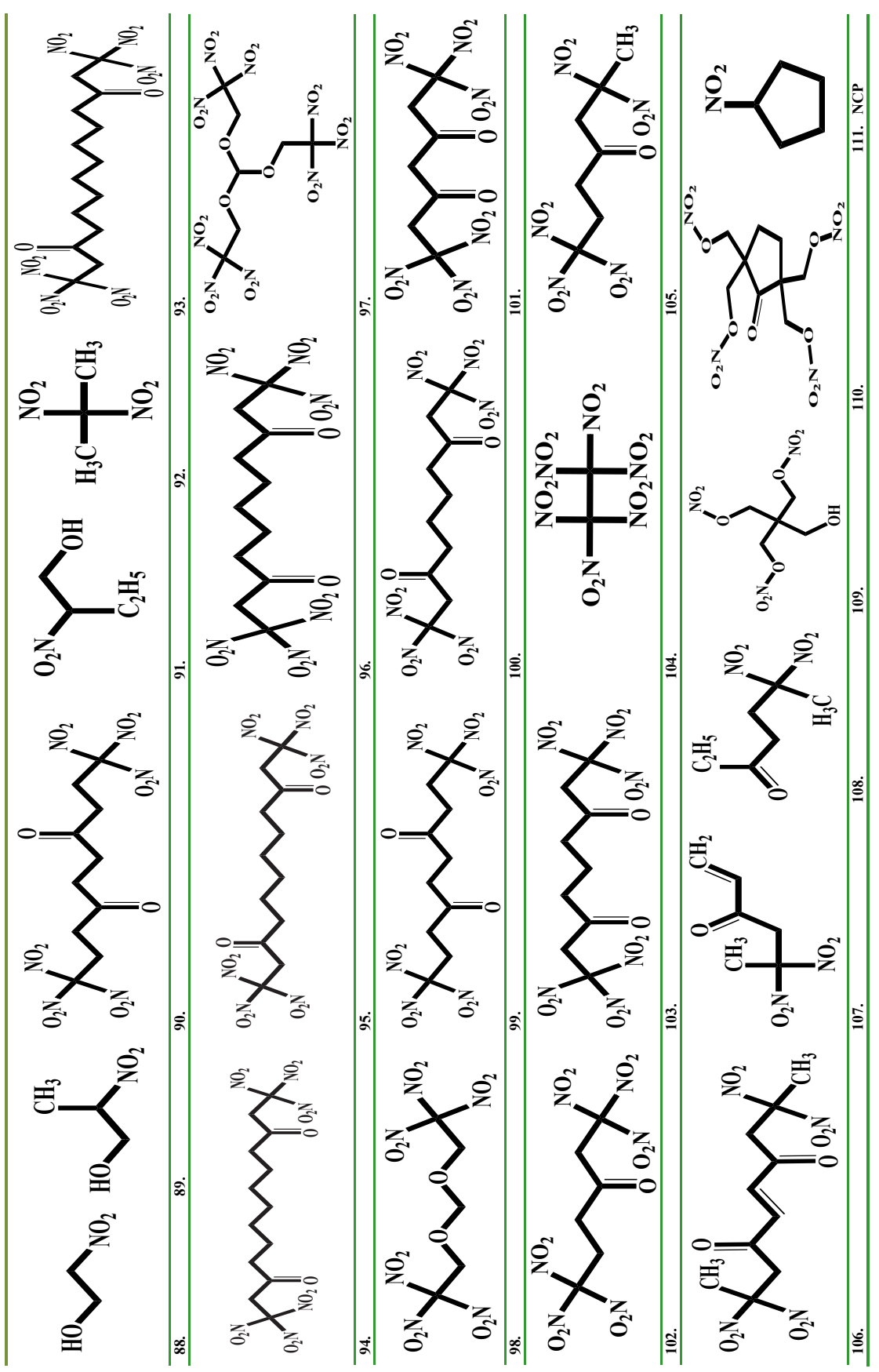


Figure 1. (Continued).

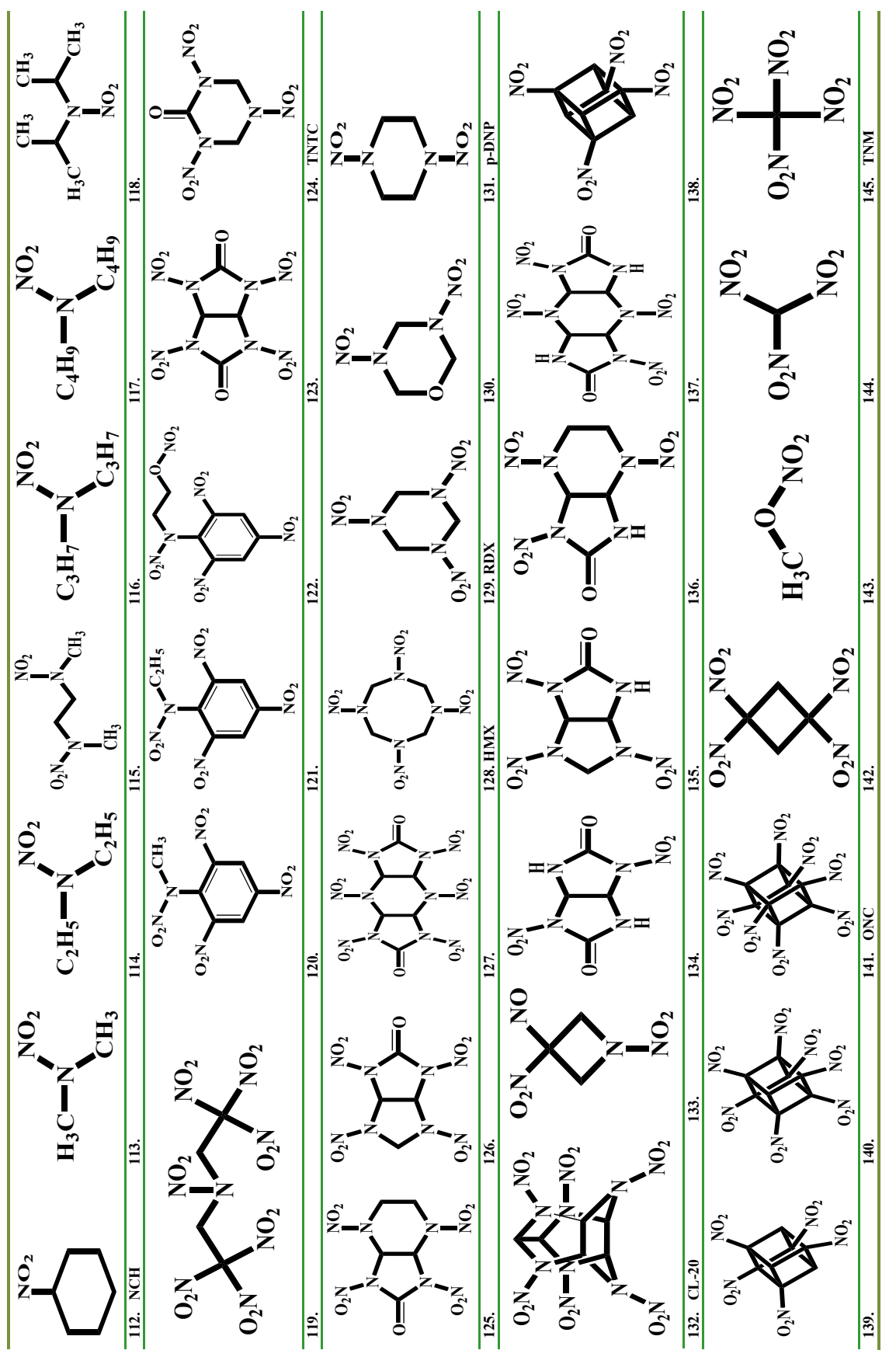


Figure 1. (Continued).

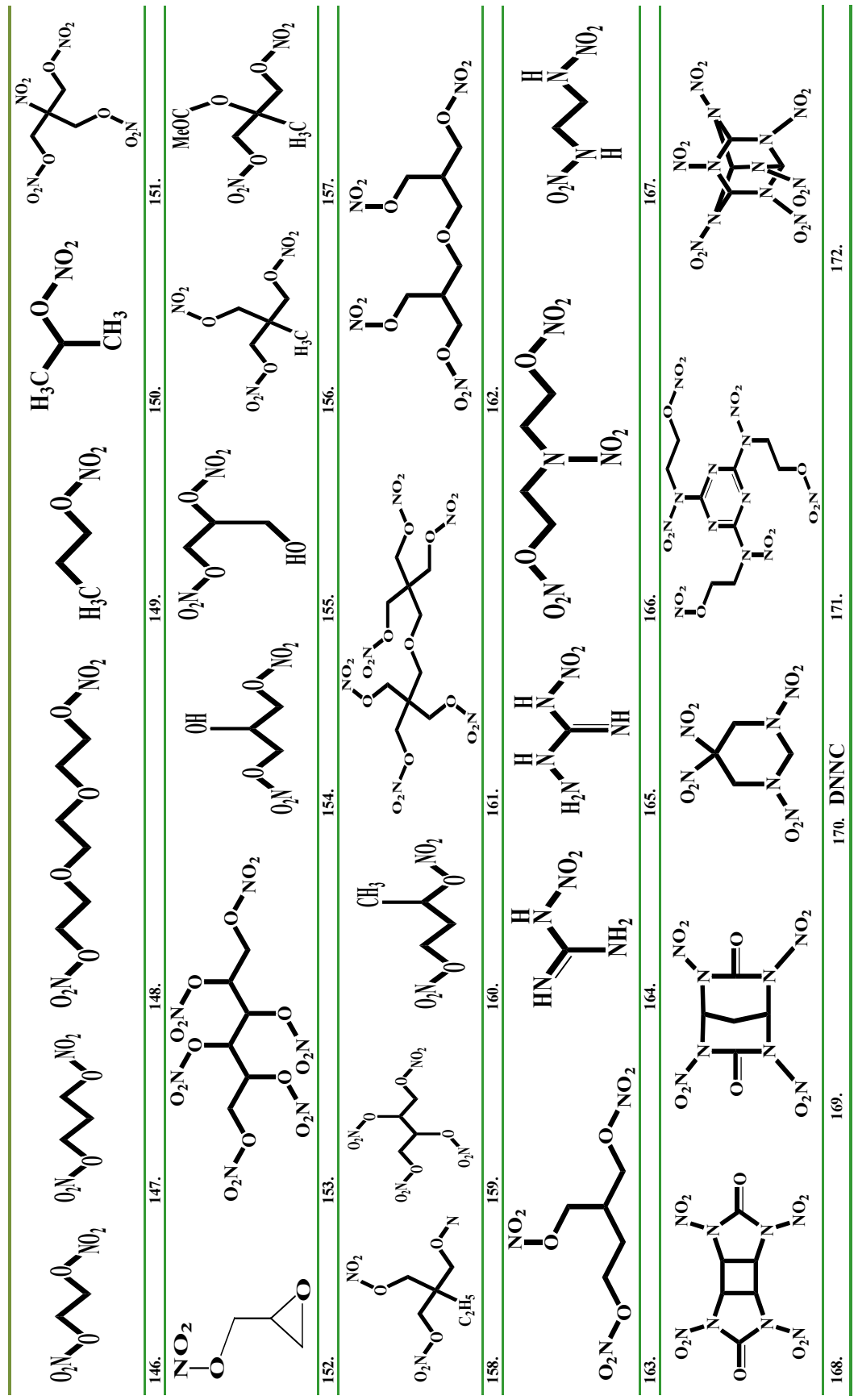




\section{Results and Discussion}

An expanded set of theoretical molecular descriptors was calculated by the DRAGON software [48] to find a relation between crystal density and the structural features of the compounds. Different aspects of the molecular structures, viewing the molecules in one, two and three dimensions, can be captured and represented by the calculated descriptors. There are two advantages in the use of exclusive theoretical descriptors: 1 ) they are free of the uncertainty of experimental measurements, and 2) they can be calculated for chemicals, which have not yet been synthesized. Given the high correlation for all of the calculated descriptors and the impossibility of conducting a MLR, because of the high number of descriptors, a variable selection procedure was essential. After the application of several MLRs [49] and ANNs on all of the calculated descriptors, the best combinations of the most relevant ones were selected for obtaining a model with the highest predictive power for crystal density.

Table 2. The correlation coefficient matrix for the descriptors used in the MLR model

\begin{tabular}{|c|c|c|c|c|c|}
\hline Symbol & Me & PW2 & IC1 & Mor32m & C-001 \\
\hline Me & 1 & & & & \\
\hline PW2 & 0.533548 & 1 & & & \\
\hline IC1 & 0.023642 & 0.215712 & 1 & & \\
\hline Mor32m & -0.29066 & 0.026259 & 0.065661 & 1 & \\
\hline C-001 & -0.59042 & -0.17095 & -0.19209 & 0.141263 & 1 \\
\hline
\end{tabular}

The selected variables and the correlation matrix of these descriptors were imagined as shown in Table 2. The selected descriptors were independent, because Table 2 shows that the correlation coefficient of each pair of descriptors was less than 0.6 , meaning there is only a weak relationship between each of the two variables. In the other words, changes in one variable are not correlated with changes in the second variable. Therefore, the (IC1 and Me) and (Mor32m and PW2) variables are not strongly correlated. If the independent variables, which are shown in Table 2, have a positive correlation coefficient, an incremental increase of one variable can increase the value of the second variable and vice versa. The multi-collinearity among the calculated descriptors was detected by calculating their variation inflation factors $(V I F)$ as follows:

$$
V I F=1 / 1-r^{2}
$$


Here, $r$ is the correlation coefficient of the multiple regressions between the variables in the model. No inter-correlation exists for a variable if VIF is equal to 1 . However, if VIF falls within the range of 1-5, the related model is acceptable; and if VIF is larger than 10, the related model is unstable and rechecking is necessary [50]. The corresponding VIF values of the five descriptors are listed in Table 3. As shown, most of the variables have $V I F$ values less than 5, indicating that the model obtained has statistical significance. In order to test the relative importance, as well as the contribution of each descriptor in the model, the value of the mean effect $(M F)$ was calculated for each descriptor as follows:

$$
M F_{j}=\beta_{j} \sum_{i=1}^{i=n} d_{i j} / \sum_{j}^{m} \beta_{j} \sum_{i}^{n} d_{i j}
$$

where: $M F_{j}$ represents the mean effect for the considered descriptor $j, \beta_{j}$ is the coefficient of the descriptor $j, d_{i j}$ stands for the value of the target descriptors for each molecule and $m$ is the descriptor number for the model. The $M F$ value indicates the relative importance of a descriptor, compared with the other descriptors in the model. Its sign shows the variation direction in the values of the properties as a result of an increase (or decrease) in the descriptor value. The mean effect values are listed in Table 3.

Table 3. Statistical parameters obtained by the MLR model

\begin{tabular}{|c|c|c|c|c|c|}
\hline Symbol & $\begin{array}{c}\text { Type of } \\
\text { descriptors }\end{array}$ & Description & $\mathrm{R}^{2}$ & $\mathrm{MF}^{\mathrm{a}}$ & $\mathrm{VIF}^{\mathrm{b}}$ \\
\hline $\mathrm{Me}$ & $\begin{array}{c}\text { Constitutional } \\
\text { descriptor }\end{array}$ & $\begin{array}{c}\text { Mean atomic Sanderson } \\
\text { electronegativity } \\
\text { (scaled on carbon atom) }\end{array}$ & 0.781 & 0.577 & 2.605 \\
\hline $\mathrm{PW} 2$ & $\begin{array}{c}\text { Topological } \\
\text { descriptor }\end{array}$ & $\begin{array}{c}\text { Path/walk }- \text { Randic } \\
\text { shape index }\end{array}$ & 0.746 & 0.355 & 1.653 \\
\hline Mor32m & $\begin{array}{c}\text { Information } \\
\text { indices } \\
\text { descriptor }\end{array}$ & $\begin{array}{c}\text { Information content index } \\
\text { (neighborhood symmetry } \\
\text { of 1-order) }\end{array}$ & 0.440 & 0.076 & 1.134 \\
\hline descriptor & $\begin{array}{c}\text { 3D-MoRSE - signal 32 } \\
\text { / weighted by atomic } \\
\text { masses }\end{array}$ & 0.016 & -0.005 & 1.175 \\
\hline & $\begin{array}{c}\text { Fragment } \\
\text { descriptor }\end{array}$ & $\begin{array}{c}\mathrm{CH}_{3} \mathrm{R} / \text { CH } \\
\text { fragments }\end{array}$ & -0.581 & -0.004 & 1.760 \\
\hline
\end{tabular}

a Mean effect;

${ }^{\mathrm{b}}$ Variation inflation factors. 


\subsection{MLR method}

As our main objective was concentrated on developing a general model, we started with a simulation on the entire data set with the selected stepwise descriptors. A better model is defined by a high value of $R^{2}$ and low values of RMSE. For the optimized model, the cross-validated coefficient $Q^{2}$ was 0.887 , and the values of RMSE for the training set and the test set were 0.089 and 0.098 , respectively. The corresponding correlation coefficients $\left(R^{2}\right)$ were 0.899 and 0.886 for the training set and the test set, respectively. An appropriate model with low standard errors and high correlation coefficients was obtained. In order to derive the best QSPR model, the MLR analysis was performed and the following MLR equation was obtained:

$\boldsymbol{\rho}_{\text {crystal }}=-4.299+3.061 \mathrm{Me}+3.620 \mathbf{P W 2}+0.181 \mathbf{I C 1}+0.143$ Mor32m $-0.070 \mathbf{C}-001$

$N_{\text {total }}=172, R_{\text {train }}^{2}=0.899, R M S E_{\text {train }}=0.090, F_{\text {train }}=233.892, Q_{L O O}^{2}=0.887$

where: $F$ is the Fisher $F$ statistic and $Q_{L O O}^{2}$ is the squared cross-validation coefficient for leave one out. The values of the selected descriptors in this model for the compounds in the training and prediction sets are listed in Table 3. Since the data set was randomly divided, during 20 rounds of cross-validation, into the training set and the test set, the averaged values of the coefficients in the different rounds were used in Equation 3.

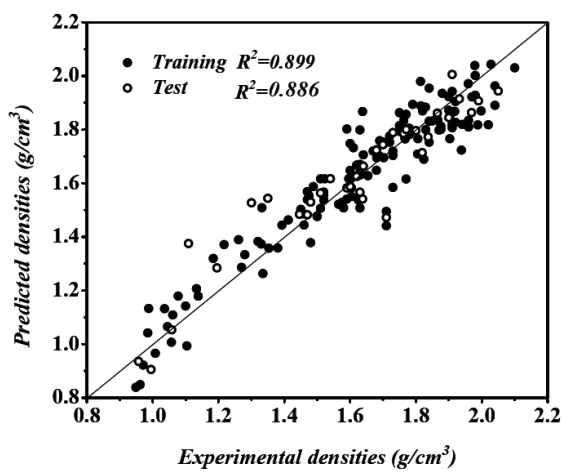

(a)

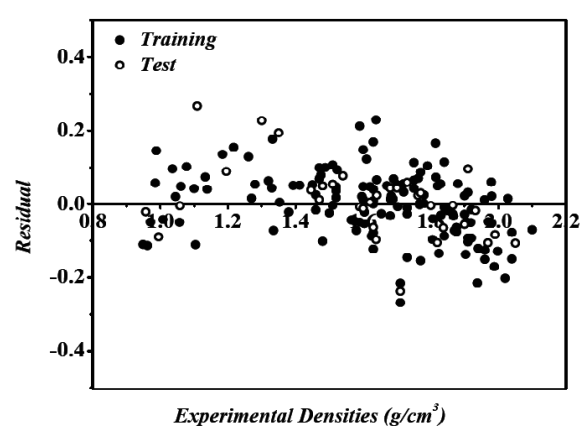

(b)

Figure 2. Plot of crystal density $\left(\mathrm{g} / \mathrm{cm}^{3}\right)$ calculated from the QSPR model, Equation 3, and the experimental values of 138 training and 34 test sets (a); the residual versus the experimental densities by MLR (b). 
Figures $2 \mathrm{a}$ and $2 \mathrm{~b}$ show the predicted values of the crystal density and the residuals of the training and test sets versus the experimental values for one round of cross validation. It can be seen from Figure $2 \mathrm{a}$ that the data are scattered about a straight line with the respective slope and intercepts close to one and zero, respectively. The robustness of the resultant model was also validated with the chance correlation procedure. The crystal density values for a set of energetic compounds were randomly proportioned to the molecular structures [50].

The five-parameter model, Equation 3, obtained based on the "breaking point" rule, was the best compromise between the correlation and the number of descriptors. Figure $2 \mathrm{~b}$ shows a plot of the residuals of the predicted values of crystal density for both the training and the test sets against the experimental crystal density values. As can be seen, the model did not show any proportional and systematic error, because the propagation of the residuals on both sides of zero was random. The real usefulness of a QSPR model is not just its ability to reproduce known data, verified by their fitting power $\left(R^{2}\right)$, but mainly its potential for predictive applications. In order to assess the robustness of the model, the Y-randomization test was applied in Table $4[51,52]$. In this test, random MLR models are generated by randomly shuffling the dependent variable while keeping the independent variables unchanged. The new QSPR models are expected to have significantly lower $\mathrm{R}^{2}$ and $\mathrm{Q}^{2}$ values for several trials, which then confirms that the developed QSPR models are robust.

Table 4. The $R_{\text {train }}^{2}$ and $Q_{L O O}^{2}$ values after several Y-randomization tests for the MLR model

\begin{tabular}{|c|c|c|}
\hline \multicolumn{3}{|c|}{ Y-randomization } \\
\hline No. & $\mathrm{Q}^{2}$ & $\mathrm{R}^{2}$ \\
\hline 1 & 0.005 & 0.060 \\
\hline 2 & 0.008 & 0.058 \\
\hline 3 & 0.000 & 0.046 \\
\hline 4 & 0.120 & 0.008 \\
\hline 5 & 0.045 & 0.019 \\
\hline 6 & 0.044 & 0.019 \\
\hline 7 & 0.000 & 0.047 \\
\hline 8 & 0.002 & 0.038 \\
\hline 9 & 0.000 & 0.041 \\
\hline 10 & 0.011 & 0.027 \\
\hline
\end{tabular}

The dependent variable vector (crystal density) was randomly shuffled and a new QSPR model was developed using the original independent variable matrix. 
The new QSPR model (after several repetitions) would be expected to have low $R^{2}$ and $Q_{L O O}^{2}$ values (Table 4). If the opposite occurs, then no acceptable QSPR model can be obtained for the specific modelling method and data. In order to evaluate the predictive power of this new model, the densities of the energetic materials were calculated by the MLR method.

\subsection{Interpretation of descriptors}

The QSPR model, in addition to demonstrating statistical significance, should also provide efficient chemical insights into the property of density. Thus, a reasonable explanation of the QSPR results is provided below. It is possible to acquire some views into the factors which are related to the crystal density, by expressing the descriptors contained in the model (brief descriptions of the descriptors are given in Table 3). The five molecular descriptors of the MLR model consist of the following:

The constitutional descriptor means the atomic Sanderson electronegativity (Me), which as it appeared in the model, is the initial significant descriptor. In this case, the Me descriptor is related to the electronegativity of the atoms. As discussed previously concerning MF, the Me mean effect has a positive sign, showing a greater MF value than that of the other descriptors. Thus, this descriptor had a significant influence on the prediction of crystal density. Regarding the positive sign, this suggests that the crystal density value is directly related to this descriptor. Consequently, an increase in the atomic electronegativity of the molecules results in increasing its crystal density.

The topological descriptor PW2 (path/walk 2-Randic shape index), which appears in the model, is the second significant descriptor. Researchers define the molecular path/walk indices as the average sum of the atomic path/walk indices of equal length. As the path/walk count ratio is independent of the molecular size, these descriptors can be considered as shape descriptors. As Table 3 shows, the mean effect of the PW2 descriptor has a positive sign, indicating that the crystal density is related directly to this descriptor; thus, increasing the size of the molecules leads to an increase in the crystal density values of the molecules.

The topological descriptor IC1 information content index (neighborhood symmetry of 1-order) is the third significant descriptor. Topological descriptors are based on a graphical representation of the molecules. They can be sensitive to size, shape, symmetry, branching and cyclicity, and can also encode chemical information concerning the atom type and bond multiplicity, as structural features of the molecules. An increase in the value of the IC1 descriptor increases the crystal density. 
The 3D Molecule Representation of Structure based on electron diffraction (3D-MoRSE) descriptor, Mor $32 \mathrm{~m}$, is the fourth significant descriptor, which provides 3D information from the three-dimensional structure of a molecule by applying a molecular transform derived from an equation used in electron diffraction studies. This can take several atomic properties into account, and therefore, gives high flexibility to this representation of a molecule. This descriptor, indicated as signal 32/weighted by atomic masses, corresponds to the atomic masses of the molecules. The mean effect of Mor $32 \mathrm{~m}$ has a negative sign, which shows that the crystal density is inversely related to this descriptor.

The final significant descriptor is the atom fragment descriptor, C-001, which expresses each atom by its own atom type as well as the bond types and atom types of its first neighbours. According to the MLR model, Equation 3, the C-001 variable, defined as the number of $\mathrm{CH}_{3} \mathrm{R} / \mathrm{CH}_{4}$ fragments (where $\mathrm{R}$ represents any group linked through carbon), has a negative effect on the crystal density of explosives. A negative mean effect shows that an increase in the number of $\mathrm{CH}_{3} \mathrm{R} / \mathrm{CH}_{4}$ fragments decreases the value of the crystal density.

\subsection{ANN method}

Computations of ANNs were done through a mathematical function which determines the activation of the neuron based on the receiving inputs and increasing them by weights (connections). The next function (which is perhaps the recognition) calculates the output of the artificial neuron. ANNs incorporate artificial neurons for processing information.

One can globally fit in the variables selector, together with a sorting utility called a "pruning" facility, which leads to using the ANNs for variable selection as a noteworthy method. Through creating networks that do not utilize certain variables as inputs, a feature selection method called Pruning is created. Thus, building new networks for each, various combinations of the input features can be added and removed.

The use of ANN is the best selection, if the idiosyncrasy of the problem indicates that the borders could be of a non-linear nature. In the event where the number of features is higher than the number of samples $(p>n)$, a previous or contemporaneous step distribution with feature selection is needed when ANN techniques are used. The principal issue is class overlap, but with proper feature selection and sufficient sample size, good classification performances can be obtained in combinatorial data $[53,54]$. The network for the calculation of the densities of energetic materials was composed of 418 inputs, 20 neurons in the hidden layer and 1 neuron in the output layer. 


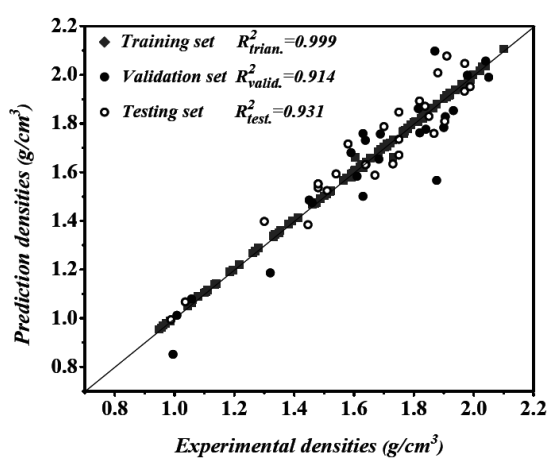

(a)

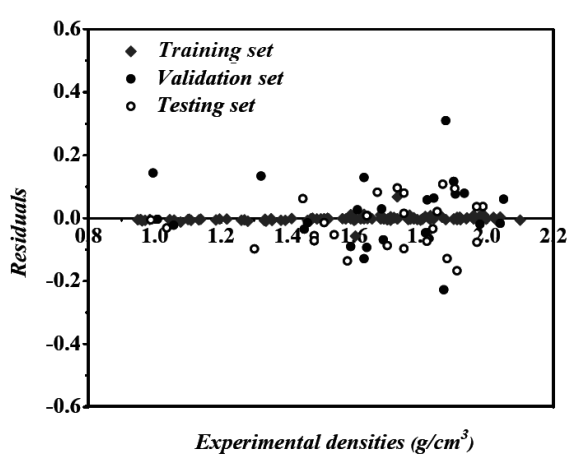

(b)

Figure 3. Plot of crystal density $\left(\mathrm{g} / \mathrm{cm}^{3}\right)$ calculated from the ANN model and the experimental values of 120 training sets, 26 validation sets and 26 test sets (a); the residual versus the experimental densities by ANN (b).

The simulation performance of the ANN model was appraised on the basis of MSE and the efficiency coefficient $\mathrm{R}^{2}$, which overall for MSE and $\mathrm{R}^{2}$ were 0.052 and 0.971 , respectively. Hence, perfect performance of the simulation was achieved. Table 1 gives the MSE and $\mathrm{R}^{2}$ values for the MLR and ANN results. The prediction of crystal density by the ANN model in the training, validation and testing sets is shown in Figure 3 (regression plot of ANN). The data set was randomly divided during 20 rounds of cross-validation into 120 training samples, 26 testing samples and 26 validation samples. It can be seen that the performance of the ANN model is perfect. However, the total population in the training process was divided into clusters. A simple random sample of the clusters was selected and named clustered data samples. Then, the MSE was decreased in a strict manner to obtain the anticipated value with fewer of epochs. The predicted densities of the energetic materials from both methods are arranged in Table 5. As seen in Table 5, the predicted values of the crystal densities of the different sets for one round of cross-validation, on the basis of data given in Figures 2 and 3, are also given.

\section{Conclusions}

This paper proposed a QSPR study of 172 energetic materials by using the MLR and ANN methods. The method of calculation developed in the present paper predicts the crystal density of any new energetic compounds which are placed 
in one of mentioned classes of energetic materials directly from the variable descriptors derived from the molecular structure. The ANN and MLR models were comprehensively assessed. The validations showed that the QSPR model was robust and satisfactory. The selected descriptors may account for the structural features responsible for the explosive properties of the compounds. The properties of the studied compounds in the MLR model were mainly related to atomic electronegativity Me, molecular size PW2, neighborhood symmetry $\mathrm{IC} 1$, atomic mass Mor32m, and the atomic fragments C-001.

Both models were used to illustrate the superiority of the ANN model over the MLR model through a comparison of the statistical parameters achieved with the training, validation and testing sets. The precision of the regular ANN training was also high due to the number of sample data points. A RMSE value of 0.052 for the prediction set by the ANN model should be compared with the value of 0.091 for the MLR model. In as much as the progress of the results received from the non-linear model (ANN) is remarkable, it can be deduced that the non-linear specifications of the principal components on the crystal density of the energetic materials is significant. This work opens up new opportunities for the valid and fast prediction of the crystal density and to the design of novel energetic materials with high performance.

\section{Acknowledgement}

We would like to thank the research committee of the University of Science and Technology, as well as Malek-ashtar University of Technology (MUT) for supporting this work. 


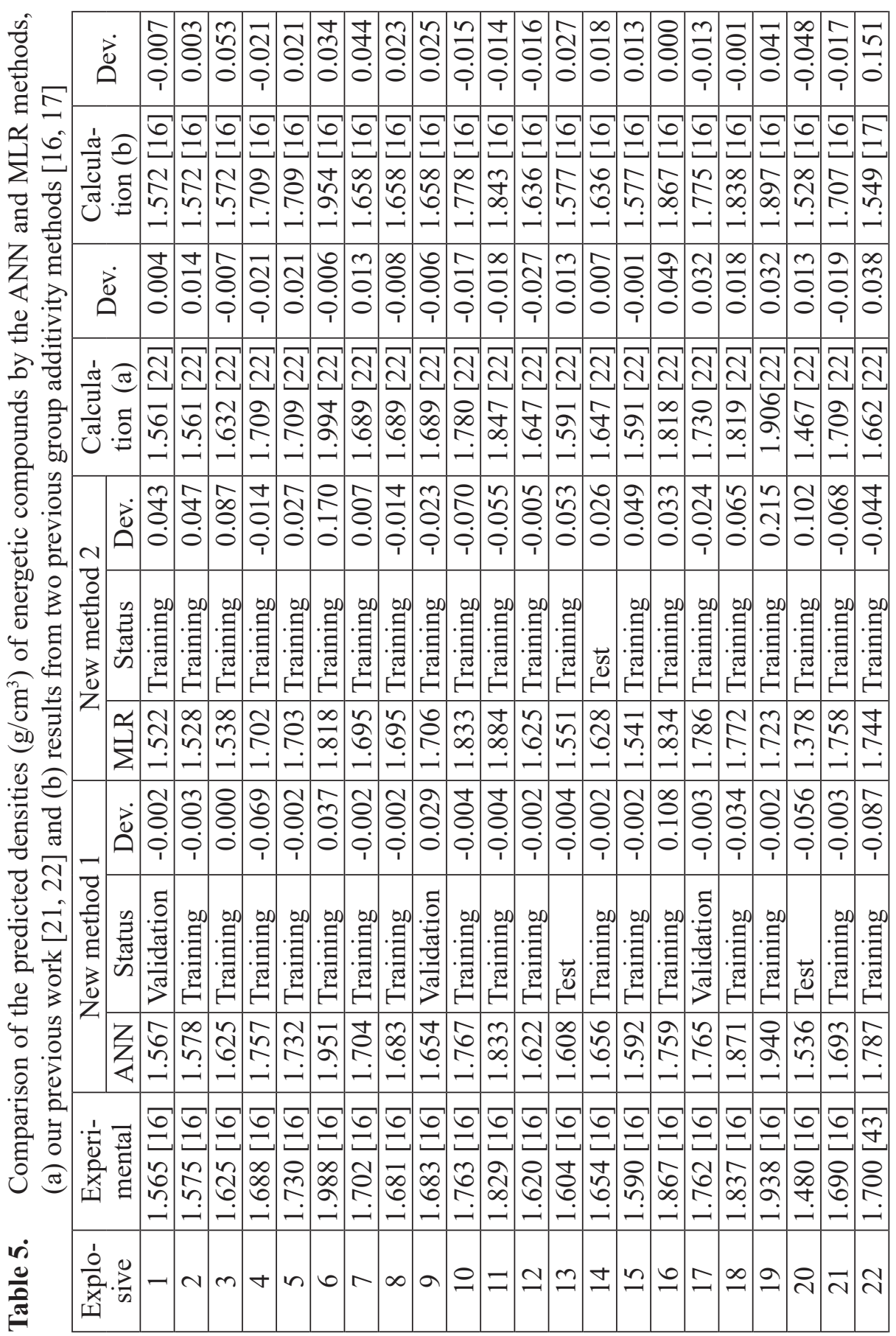




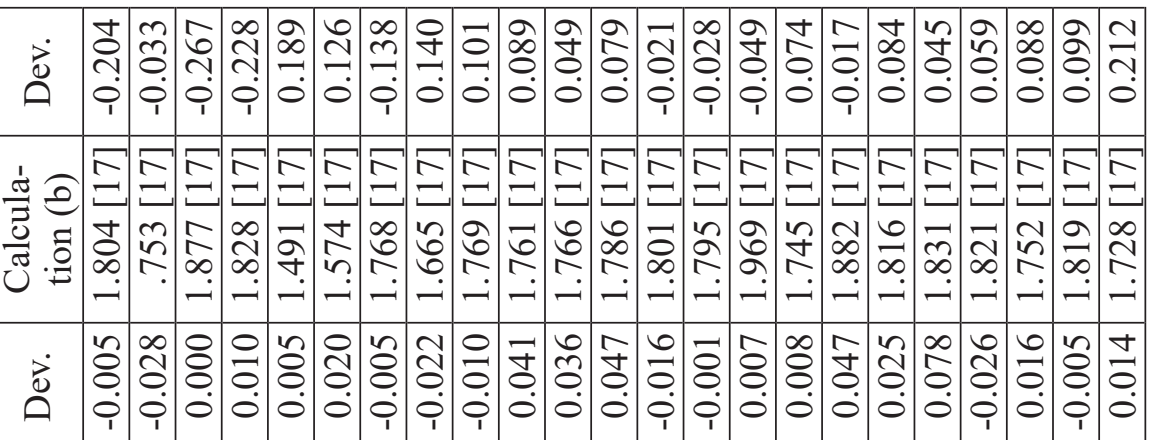
宗

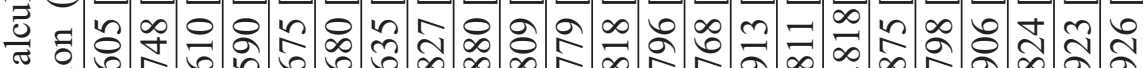
U઼

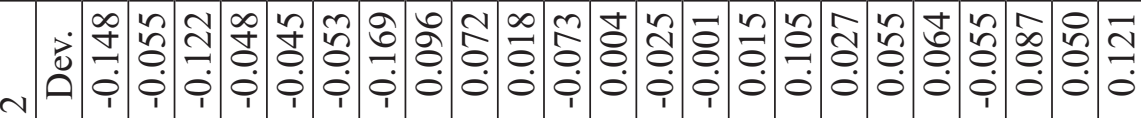

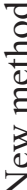

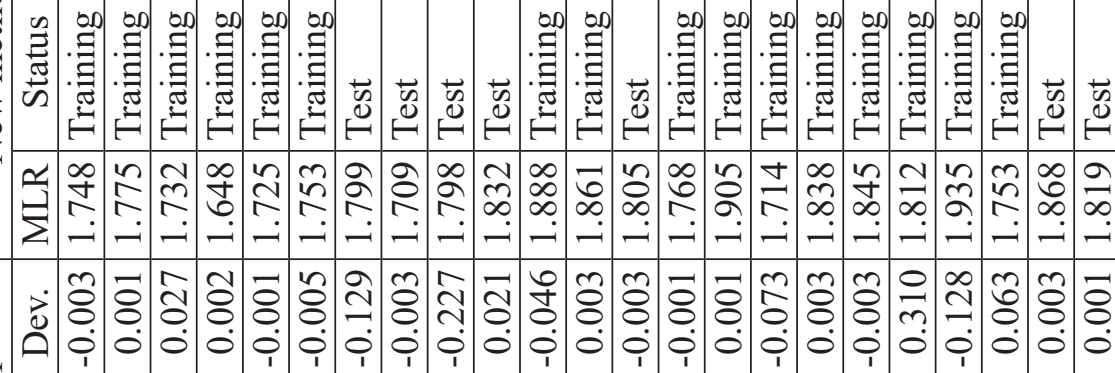
등

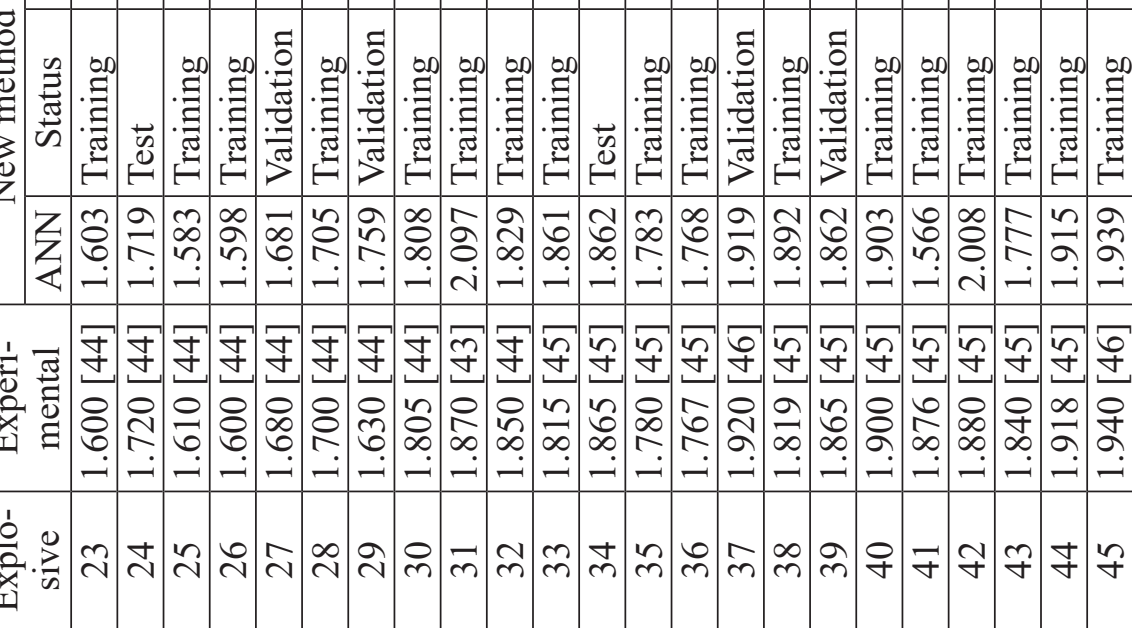




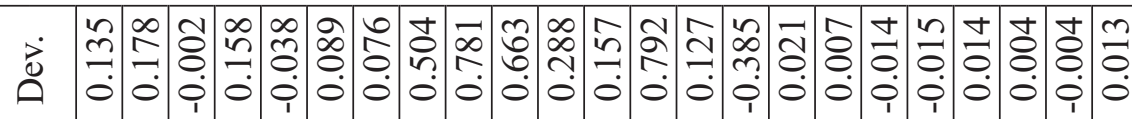

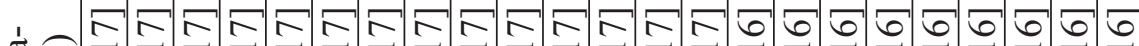
声 U

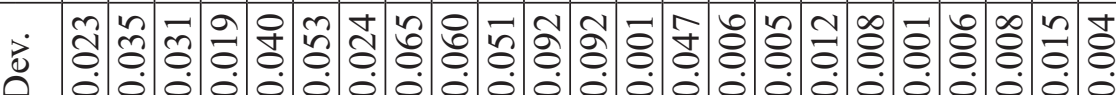

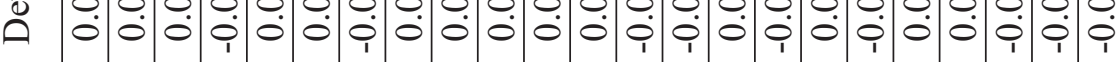

่ J U. - 0000000

خ்

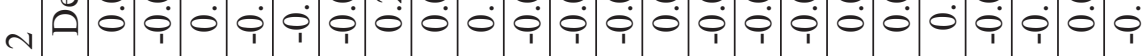

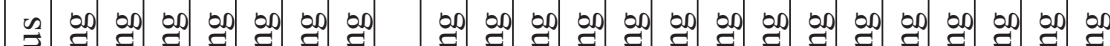
芯

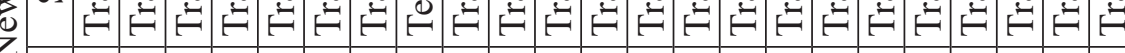
我

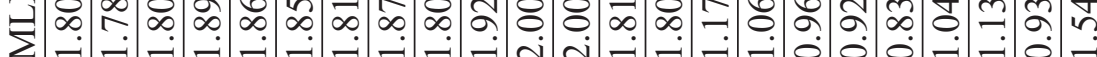

n ¿

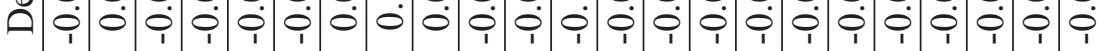

च

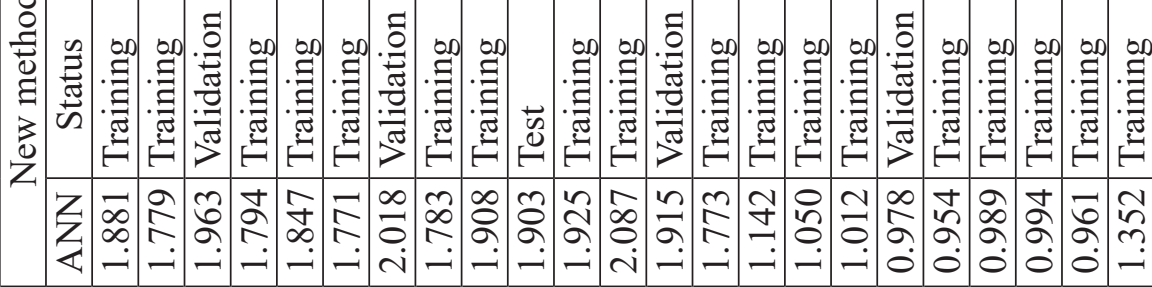

·

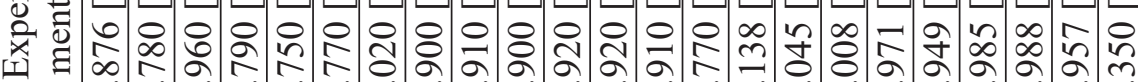

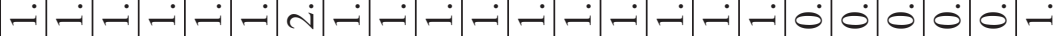

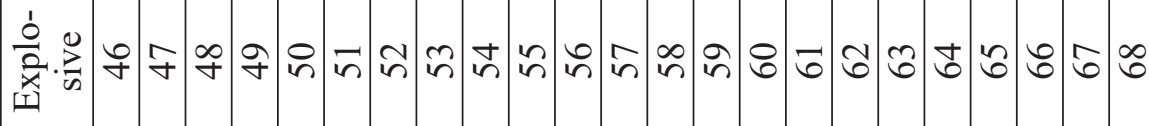




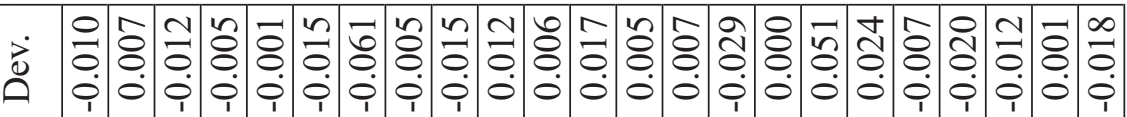

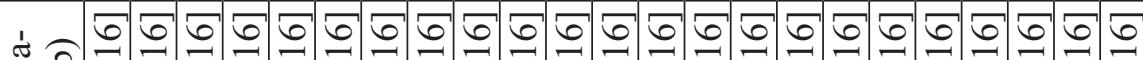

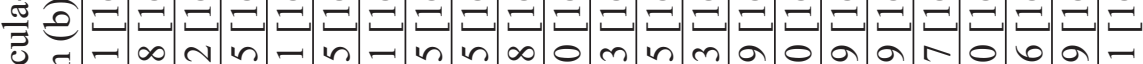

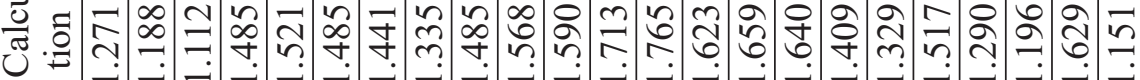

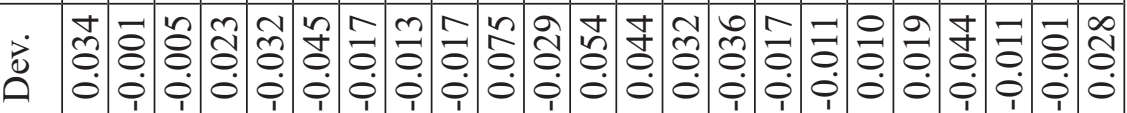

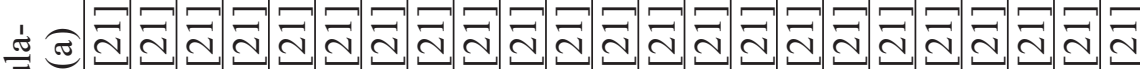

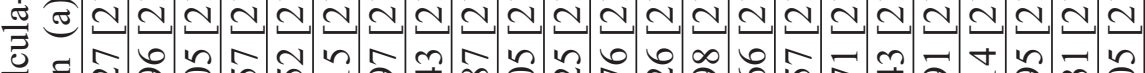

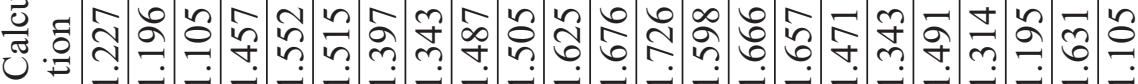

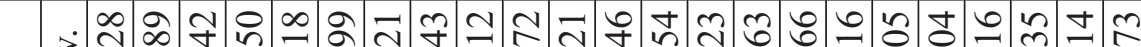

己니 강

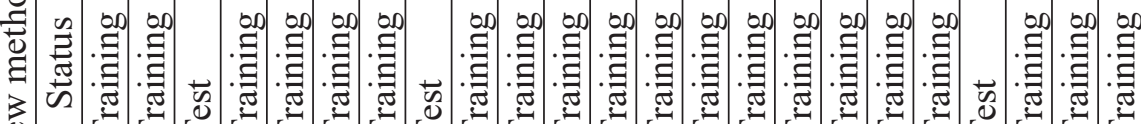
Z 平

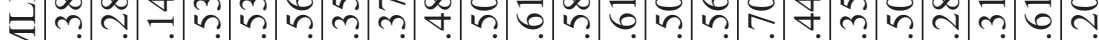
$\Sigma-\dot{-}-\dot{-}-\dot{-}-\dot{-}-\dot{-}-\dot{-}-\dot{-}-\dot{-}-\dot{-}-\dot{-}$

. ঊ $-$

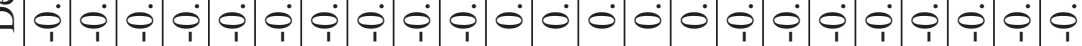

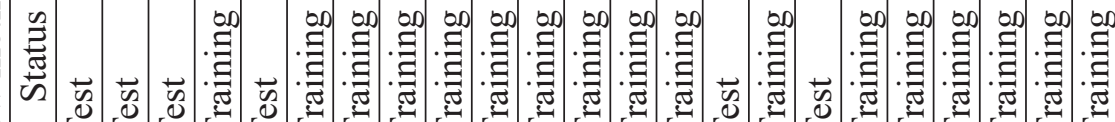

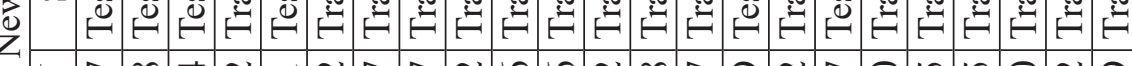
Z

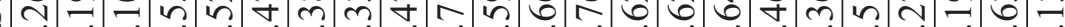

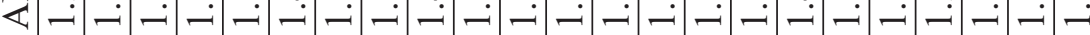

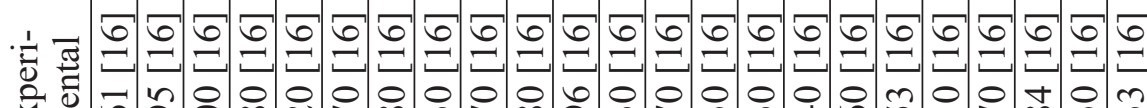

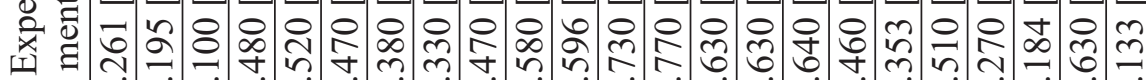

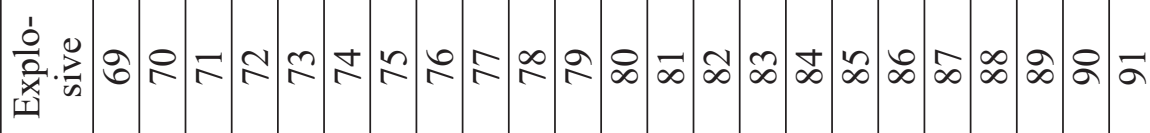




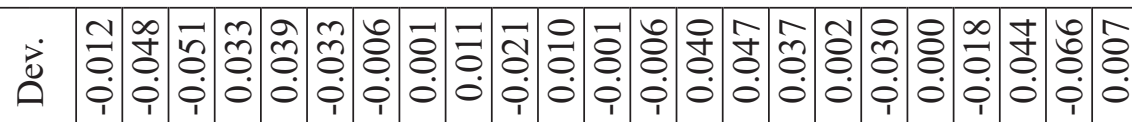
을

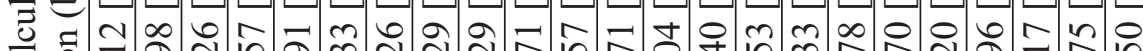
U

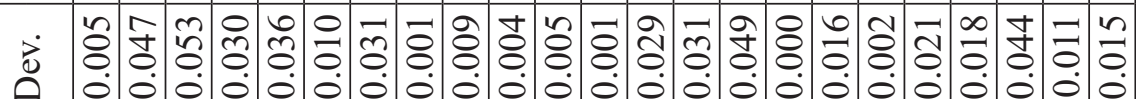

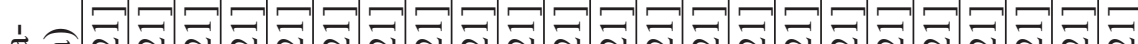

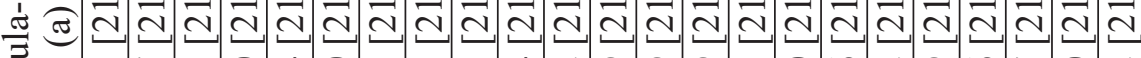

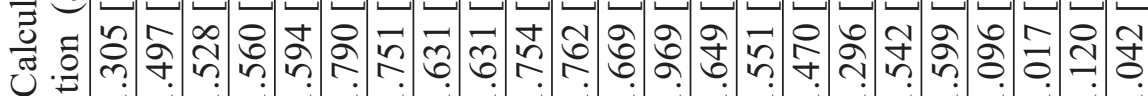
- Na N

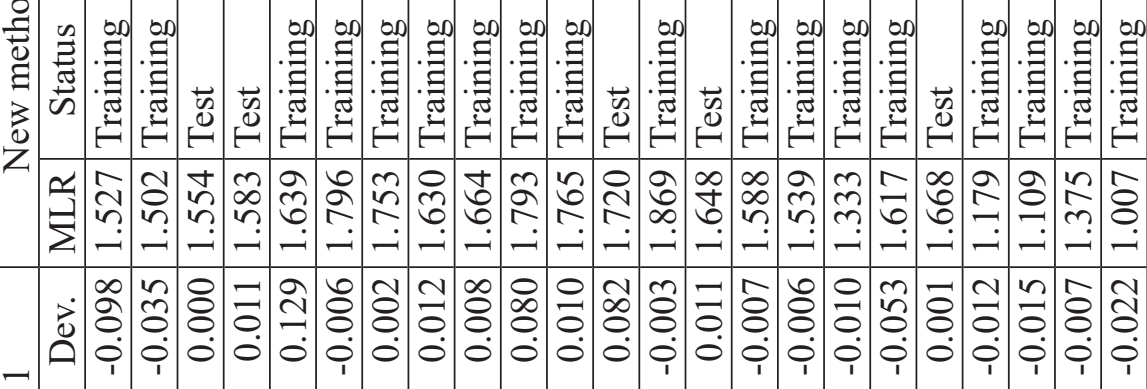

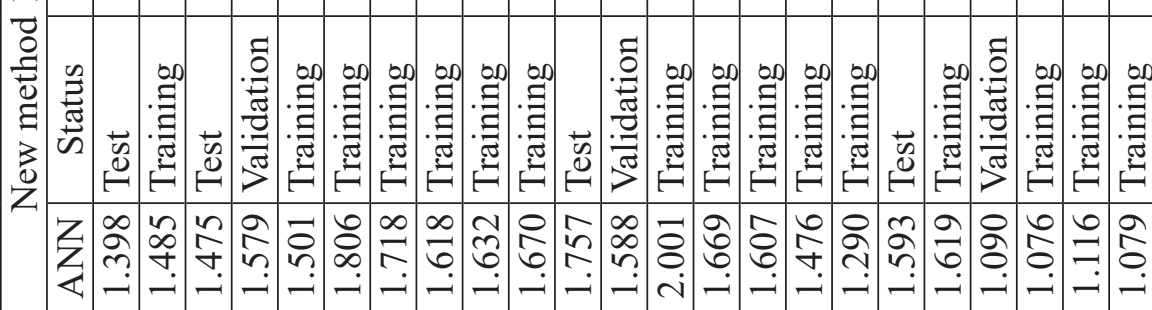

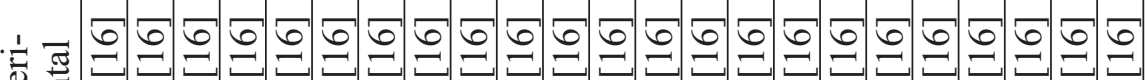

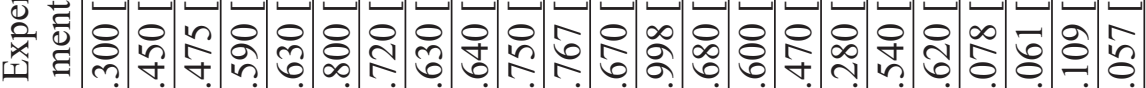
$-\dot{-}-\dot{-}-\dot{-}-\dot{-}-\dot{-}-\dot{-}-\dot{-}-\dot{-}-\dot{-}-\dot{-}-\dot{-}-\dot{-}$

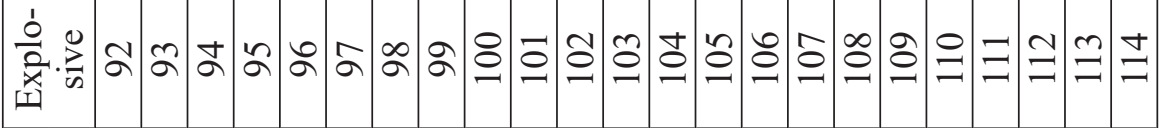




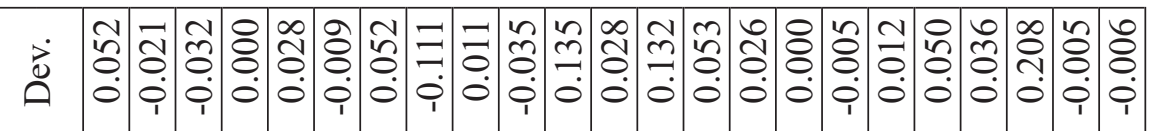

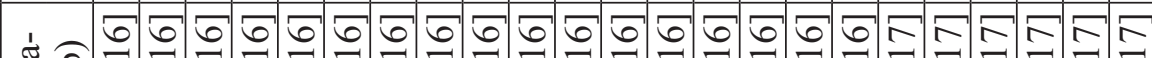

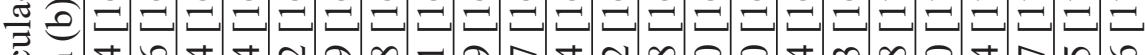
ส

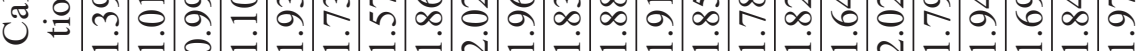

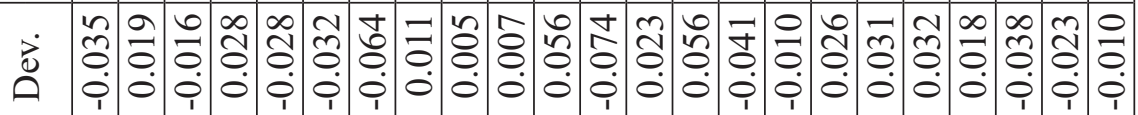

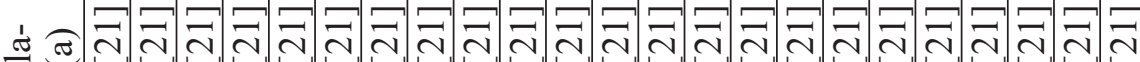
盯 光

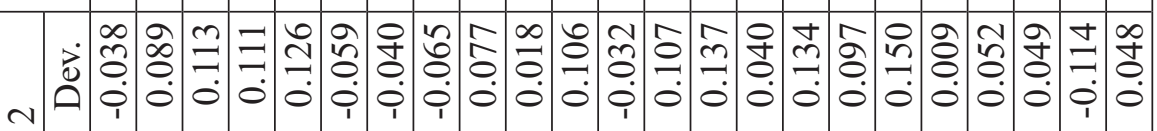
כ)

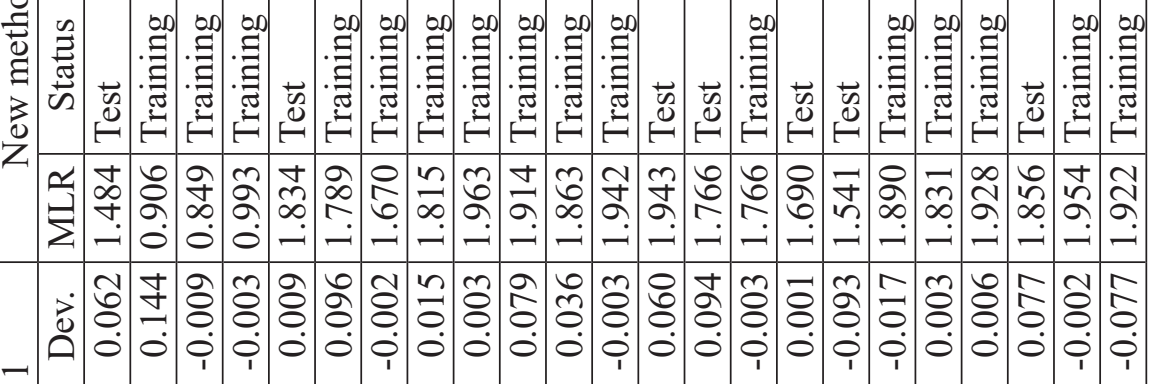

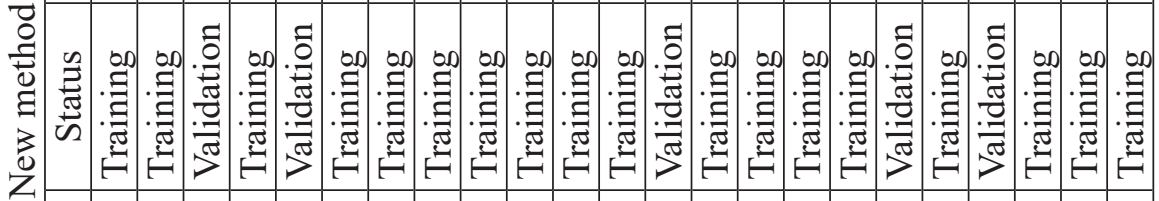
Z古

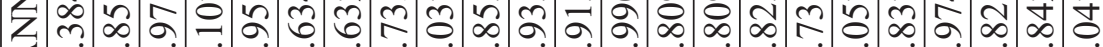

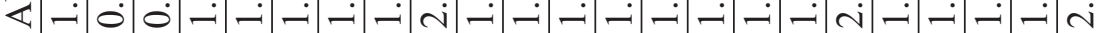
·

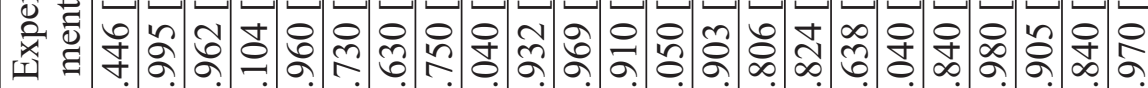

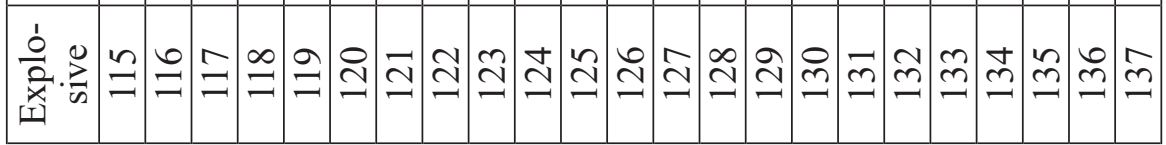




\begin{tabular}{|c|c|c|c|c|c|c|c|c|c|c|c|c|c|c|c|c|c|c|c|c|c|c|}
\hline రి & & 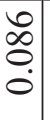 & & & $\begin{array}{l}\infty \\
0 \\
0 \\
0\end{array}$ & i & $\begin{array}{c} \\
0 \\
n \\
0 \\
1\end{array}$ & & & & i & & & 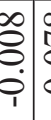 & & $\begin{array}{ll}5 \\
5 \\
\vdots \\
\vdots \\
1\end{array}$ & & $\hat{i}$ & 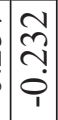 & & 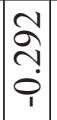 & \\
\hline . & $\begin{array}{l}0 \\
0 \\
\infty\end{array}$ & $m$ & & & ؟ & - & 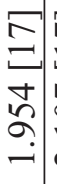 & & & $-\dot{\sim}$ & $-i$ & 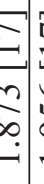 & - & - & & $\begin{array}{l}0 \\
0 \\
0 \\
0 \\
0\end{array}$ & 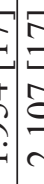 & & 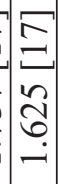 & 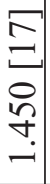 & חִ & \\
\hline $\overrightarrow{0}$ & $\left|\begin{array}{c}\hat{2} \\
0 \\
0 \\
1 \\
1\end{array}\right|$ & $\begin{array}{l}0 \\
0 \\
0 \\
0\end{array}$ & $\begin{array}{l}0 \\
0 \\
0 \\
0 \\
0\end{array}$ & & 宫 & $\begin{array}{l}\tilde{\sigma} \\
0 \\
0 \\
0\end{array}$ & $\begin{array}{c}n \\
\tilde{0} \\
0 \\
1\end{array}$ & $\begin{array}{l}\dot{J} \\
\vdots \\
\dot{0}\end{array}$ & $\begin{array}{l}\widetilde{\Omega} \\
0 \\
\dot{0}\end{array}$ & $\begin{array}{l}0 \\
0 \\
0 \\
\dot{1} \\
1\end{array}$ & $\begin{array}{l}0 \\
0 \\
0\end{array}$ & '. & 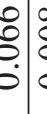 & 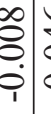 & & 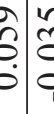 & & 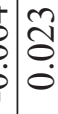 & $\begin{array}{l}\infty \\
\tilde{n} \\
0 \\
0 \\
0\end{array}$ & $\begin{array}{l}0 \\
\dot{J} \\
\dot{0}\end{array}$ & $\begin{array}{c}1 \\
8 \\
0 \\
0 \\
1\end{array}$ & \\
\hline & $\vec{\sim}$ & & & $\mathrm{N}$ & $\vec{\sim}$ & & & & & $\vec{\sim}$ & $\bar{N}$ & $\vec{\nabla}$ & $\overline{2}$ & & & $\bar{\nabla} \bar{\sigma}$ & $1 / 0$ & $\vec{\sim}$ & $\bar{\nabla}$ & & $\bar{\sim}$ & \\
\hline s. & $\begin{array}{l}\infty \\
\infty \\
-\end{array}$ & $\begin{array}{l}\text { § } \\
\infty \\
-1\end{array}$ & $\begin{array}{l}\text { ஸै } \\
\text { ๙ุ }\end{array}$ & $\hat{\infty}$ & 声 & 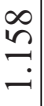 & $\begin{array}{l}\tilde{2} \\
\tilde{\sigma} \\
-\end{array}$ & ç & $\stackrel{\sqrt[n]{f}}{-}$ & 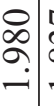 & $-i$ & . & ?2: & ְ. & & 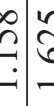 & & 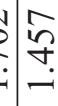 & $\begin{array}{l}n \\
n \\
n \\
-1\end{array}$ & $\begin{array}{l}0 \\
\infty \\
\text { N̦ } \\
-\end{array}$ & $\begin{array}{l}n \\
0 \\
0 \\
-1\end{array}$ & \\
\hline & $\begin{array}{c}0 \\
0 \\
0 \\
0 \\
1 \\
1\end{array}$ & $\begin{array}{c}N \\
0 \\
0 \\
0 \\
1\end{array}$ & \begin{tabular}{|c|}
$n$ \\
0 \\
0 \\
0 \\
1
\end{tabular} & & ○్ & $\begin{array}{l}n \\
\stackrel{n}{n} \\
\dot{1}\end{array}$ & 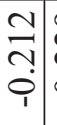 & 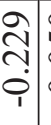 & & & $\begin{array}{l}0 \\
0 \\
0 \\
0 \\
1\end{array}$ & ب. & $\frac{1}{6}$ & $\begin{array}{l}0 \\
0 \\
0 \\
0 \\
\end{array}$ & & & & & $\begin{array}{l}\vec{n} \\
0 \\
0 \\
1\end{array}$ & $N$ & & \\
\hline & 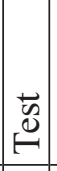 & $\stackrel{\overrightarrow{\tilde{\theta}}}{\oplus}$ & 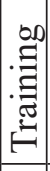 & 寻 & 馬 & $\stackrel{\overrightarrow{0}}{\tilde{\theta}}$ & 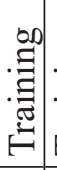 & $\stackrel{\pi}{\pi}$ & 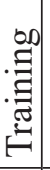 & 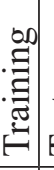 & $\stackrel{\overrightarrow{0}}{-1}$ & 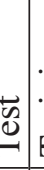 & : & 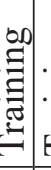 & & $\begin{array}{lll}\vec{b} \\
0\end{array}$ & 15 & 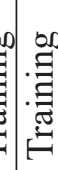 & . & 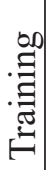 & 䲮 & \\
\hline & $\mid$\begin{tabular}{l}
0 \\
2 \\
\hdashline \\
-1
\end{tabular} & $\vec{\sigma}$ & $\stackrel{m}{q}$ & & $\begin{array}{l}8 \\
\infty \\
-\end{array}$ & $\underset{\overbrace{}}{\vec{n}}$ & $\begin{array}{l}\text { ते } \\
\infty \\
-1\end{array}$ & $\overline{6}$ & $\begin{array}{l}0 \\
n \\
n \\
\end{array}$ & & \begin{tabular}{l}
0 \\
$\infty$ \\
\hdashline \\
-
\end{tabular} & 5 & $N \mid$ & 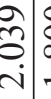 & & & $-1-$ & & $\underset{-}{+}$ & -1 & $\left|\begin{array}{c}n \\
\tilde{o} \\
-1\end{array}\right|$ & \\
\hline & $\curvearrowleft$ & 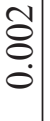 & $\mid \begin{array}{l}0 \\
0 \\
0 \\
0 \\
1 \\
1\end{array}$ & O. & ○. & $\begin{array}{l}0 \\
8 \\
0 \\
0 \\
1\end{array}$ & $\begin{array}{l}\stackrel{2}{0} \\
0 \\
0 \\
1\end{array}$ & $\dot{0}$ & $\begin{array}{l}\mathbb{N} \\
0 \\
0 \\
1\end{array}$ & $\begin{array}{l}\hat{2} \\
0 \\
0 \\
1\end{array}$ & \begin{tabular}{l}
$\mathscr{8}$ \\
\hdashline \\
\hdashline
\end{tabular} & 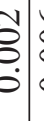 & '. & $\begin{array}{l}0 \\
\vdots \\
0 \\
\\
\end{array}$ & & & & 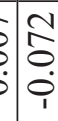 & $\begin{array}{l}1 \\
0 \\
0 \\
\dot{0}\end{array}$ & ò & $\dot{0}$ & \\
\hline 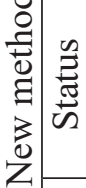 & 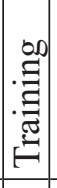 & $F$ & $\theta$ & $\stackrel{6}{e}$ & 节 & 鞄 & . & & 量 & 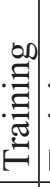 & $\exists$ & $\stackrel{0}{=0}$ & $=$ & $E$ & 胥 & 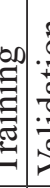 & 1 & 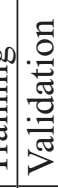 & 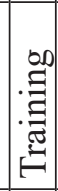 & $F$ & 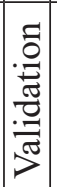 & $\mathrm{H}$ \\
\hline 2 & - & ñ & $\stackrel{+}{m}$ & & 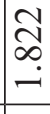 & 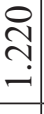 & $\begin{array}{l}\infty \\
\infty \\
0 \\
-\end{array}$ & శூ & $\begin{array}{l}\mathfrak{n} \\
n \\
\\
-\end{array}$ & $\begin{array}{l}\tilde{J} \\
0 \\
ن\end{array}$ & & & i & $\begin{array}{l}\infty \\
\text { aे } \\
\text { a }\end{array}$ & & $\begin{array}{l}2 \\
v \\
\\
\end{array}$ & & & \begin{tabular}{l}
8 \\
$\stackrel{8}{\circ}$ \\
\hdashline \\
\end{tabular} & - & $\begin{array}{c}\tilde{J} \\
0 \\
0 \\
-\end{array}$ & \\
\hline$\frac{\vec{d}}{4} \overrightarrow{ \pm}$ & ¿ & $\stackrel{n}{ \pm}$ & 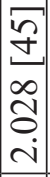 & $\stackrel{n}{ \pm}$ & ర్ & 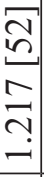 & 8 & $\begin{array}{c}\infty \\
m\end{array}$ & $\infty$ & $\begin{array}{c} \pm \\
\varrho \\
\varrho \\
\end{array}$ & \pm & \& & $\begin{array}{l}\dot{y} \\
\infty \\
v\end{array}$ & $\frac{8}{8}$ & I & i & dy & 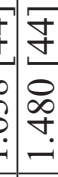 & {$\left[\begin{array}{c}\tilde{\Omega} \\
\tilde{-}\end{array}\right.$} & $\begin{array}{l}\text { m. } \\
\text { m. }\end{array}$ & $\mid \begin{array}{l} \pm \\
\infty \\
\curvearrowleft \\
0 \\
-\end{array}$ & \\
\hline$\frac{\pi}{4} \cdot \frac{\pi}{\infty}$ & & & & & & & & & & & & & & & & & & & \pm & & \pm & \\
\hline
\end{tabular}




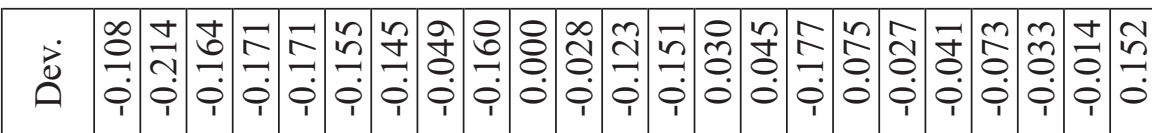

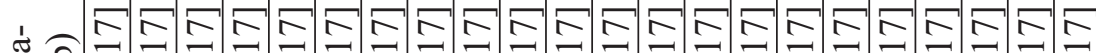

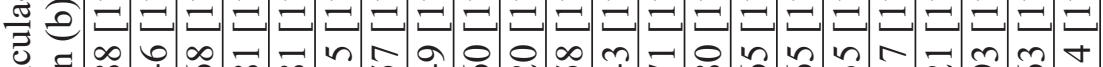

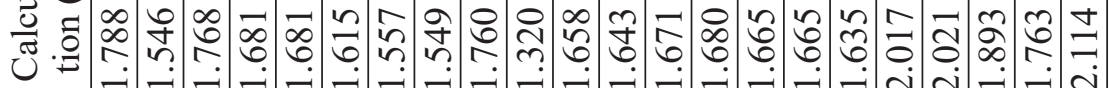

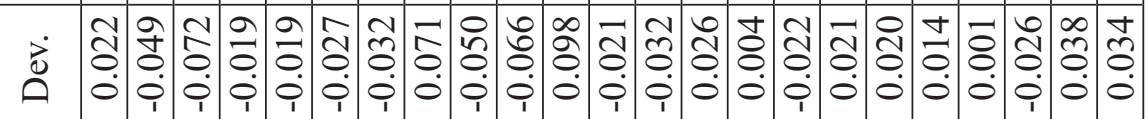

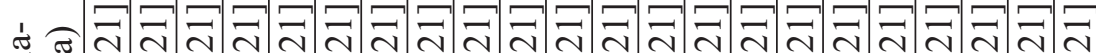

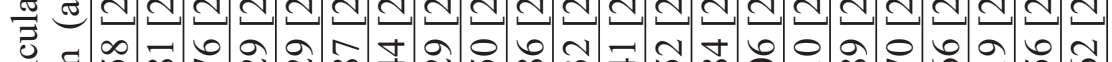

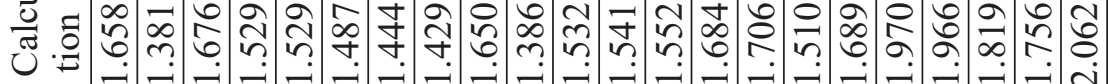

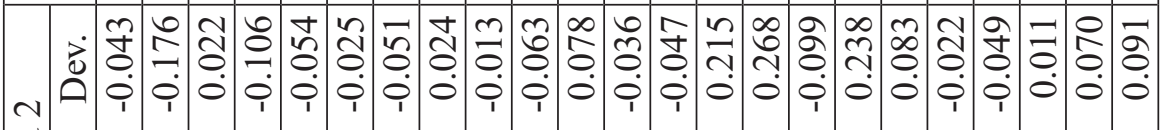

ㅁำ

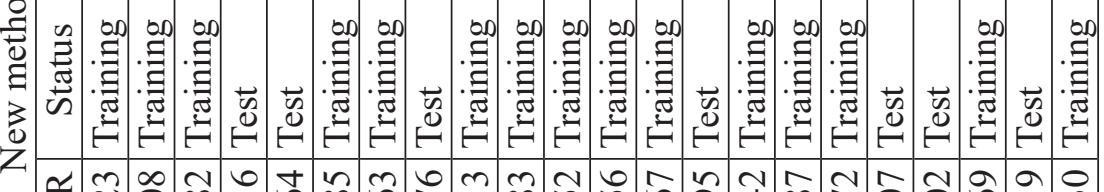

뜨 $\infty$ 잉

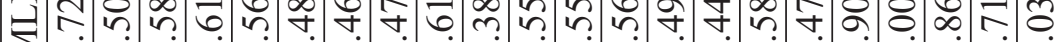

c.t八

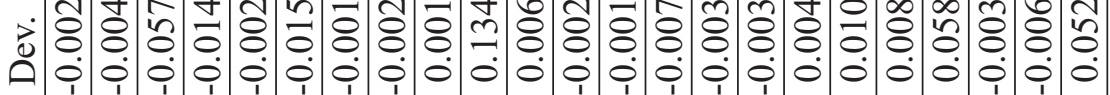
$\rightarrow$

פ

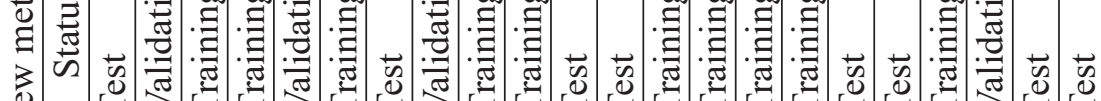

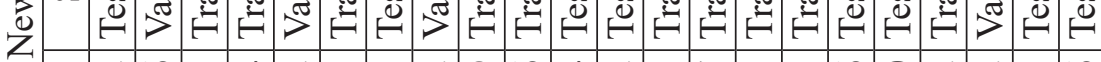

Z

Z

$\varangle-\dot{-}-\dot{-}-\dot{-}-\dot{-}-\dot{-}-\dot{-}-\dot{-}-\dot{-}-\dot{-} \dot{-}$ i

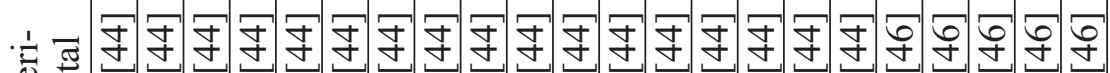

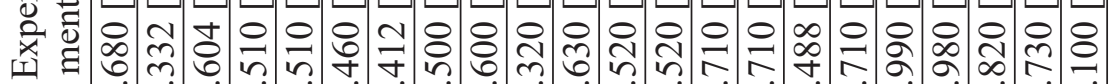

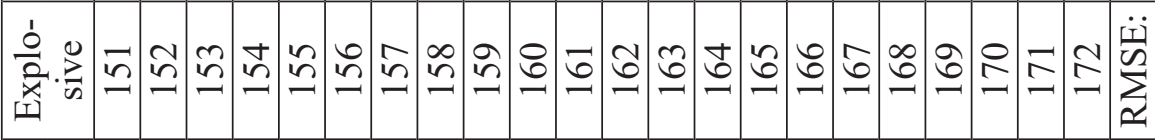




\section{References}

[1] Keshavarz M.H., A Simple Theoretical Prediction of Detonation Velocities of Non-ideal Explosives only from Elemental Composition, in: New Research on Hazardous Materials, (Warey P.B., Ed.), Nova Science Publishers, 2007, Ch. 9, pp. 293-310; ISBN 1-60021-256-5.

[2] Fried L.E., Howard W.M., Souers P.C., CHEETAH 2.0 User's Manual, Lawrence Livermore National Laboratory, Livermore, CA, 1998; UCRL-MA-117541-Rev. 5.

[3] Sikder A.K., Maddala G., Agrawal J.P., Singh H., Important Aspects of Behavior of Organic Energetic Compounds: A Review, J. Hazard. Mater. A, 2001, 84, 1-26.

[4] Agrawal J.P., High Energy Materials, WILEY-VCH, Weinheim, 2010; ISBN 9783-527-32610-5.

[5] Keshavarz M.H., Explosive Materials, (Janssen T.J., Ed.), Nova Science Publishers, Hauppauge, New York, 2011, pp. 179; ISBN 978-1-61761-188-9.

[6] Keshavarz M.H., Research Progress on Heats of Formation and Detonation of Energetic Compounds, Hazardous Materials: Types, Risks and Control, (Brar S.K., Ed.), Nova Science Publishers, New York, 2011, pp. 339-359; ISBN 978-1-62417518-3.

[7] Agrawal J.P., Hudgson R.D., Organic Chemistry of Explosives, John Wiley \& Sons, West Sussen, 2007; ISBN 0-470-02967-6.

[8] Stine J.R., Prediction of Crystal Densities of Organic Explosives by Group Additivities, Los Alamos National Laboratory, 1981; LA-8920, UC-45.

[9] Ammon H.L., New Atom/Functional Group Volume Additivity Data Bases for the Calculation of the Crystal Densities of C-, H-, N-, O-, F-, S-, P-, Cl-, and Brcontaining Compounds, Struct. Chem., 2001, 21, 205-212.

[10] Sorescu D.C., Rice B.M., Thompson D.L., Theoretical Studies of Solid Nitromethane, J. Phys. Chem. B, 2000, 104, 8406.

[11] Sorescu D.C., Rice B.M., Thompson D.L., Decomposition, Crystal and Molecular Properties, in: Energetic Materials. Part 1., (Politzer P., Murray J.S., Eds.), Elsevier, Amsterdam, 2003, Ch. 6; ISBN 978-0-444-51518-6.

[12] Kim C.K., Cho S.G., Kim C.K., Park H.Y., Zhang H., Lee H.W., Prediction of Densities for Solid Energetic Molecules with Molecular Surface Electrostatic Potentials, J. Comput. Chem., 2008, 29, 1818.

[13] Rice B.M., Hare J.J., Byrd E.F.C., Accurate Predictions of Crystal Densities Using Quantum Chemical Molecular Volumes, J. Phys. Chem. A, 2007, 111, 10874-10879.

[14] Qiu L., Xiao H., Gong X., Ju X., Zhu W., Crystal Density Predictions for Nitramines Based on Quantum Chemistry, J. Hazard. Mater., 2007, 141, 280-288.

[15] Politzer P., Martinez J., Murray J.S., Concha M.C., Toro-Labbé A., An Electrostatic Interaction Correction for Improved Crystal Density Predictions, Mol. Phys., 2009, 107, 2095-2101.

[16] Tarver C.M., Density Estimation for Explosives and Related Compounds Using the Group Additivity Approach, J. Chem. Eng. Data, 1979, 24, 136-145.

[17] Ammon H.L., Updated Atom/Functional Group and Atom Code Volume Additivity 
Parameters for the Calculation of Crystal Densities of Single Molecules, Organic Salts, and Multi-Fragment Materials Containing, H, C, B, N, O, F, S, P, Cl, Br and I, Propellants Explos. Pyrotech., 2008, 33, 92-102.

[18] Willer R.L., Calculation of the Density and Detonation Properties of C, H, N, O and F Compounds: Use in the Design and Synthesis of New Energetic Materials, J. Mex. Chem. Soc., 2009, 53, 108-119.

[19] Keshavarz M.H., Predictions of Densities of Acyclic and Cyclic Nitramines, Nitrate Esters and Nitroaliphatic Compounds for Evaluation of their Detonation Performance, J. Hazard. Mater., 2007, 143, 437-442.

[20] Keshavarz M.H., New Method for Calculating Densities of Nitroaromatic Explosive Compounds, J. Hazard. Mater., 2007, 145, 263-269.

[21] Keshavarz M.H., Pouretedal H.R., A Reliable Simple Method to Estimate Density of Nitroaliphatics, Nitrate Esters and Nitramines, J. Hazard. Mater, 2009, 169, 158-169.

[22] Keshavarz M.H., Novel Method for Predicting Densities of Polynitro Arene and Polynitro Heteroarene Explosives in Order to Evaluate Their Detonation Performance, J. Hazard. Mater., 2009, 165, 579-588.

[23] Cho S.G., Goh E.M., Kim J.K., Holographic QSAR Models for Estimating Densities of Energetic Materials, Bull. Kor. Chem. Soc., 2001, 22, 775-778.

[24] Karfunkel H.R., Gdanitz R.J., Ab initio Prediction of Possible Crystal Structures for General Organic Molecules, J. Comput. Chem., 1992, 13, 1171-1183.

[25] Bartošková M., Friedl Z., The Relationship between the Heats of Formation and the Molecular Electrostatic Potentials of Polyazaarenes, Cent. Eur. J. Energ. Mater, 2013, 10, 103-112.

[26] Morrill J.A., Byrd E.F., Development of Quantitative Structure-Property Relationships for Predictive Modeling and Design of Energetic Materials, J. Mol. Graph. Model., 2008, 27, 349-355.

[27] Fayet G., Rotureau P., Development of Simple QSPR Models for the Impact Sensitivity of Nitramines, J. Loss Prevet. Proc., 2014, 30, 1-8.

[28] Keshavarz M.H., Motamedoshariati H., Moghayadnia R., Ghanbarzadeh M., Azarniamehraban J., Prediction of Sensitivity of Energetic Compounds with a New Computer Code, Propellants Explos. Pyrotech., 2014, 39, 95-101.

[29] Bagheri M., Gandomi A.H., Bagheri M., Shahbaznezhad M., Multi-expression Programming Based Model for Prediction of Formation Enthalpies of NitroEnergetic Materials, Expert Systems, 2013, 30, 66-78.

[30] Yan Q.L., Zeman S., Theoretical Evaluation of Sensitivity and Thermal Stability for High Explosives Based on Quantum Chemistry Methods: a Brief Review, Int. J. Quant. Chem., 2013, 113, 1049-1061.

[31] Cocchi M., De Benedetti P.G., Seeber R., Tassi L., Ulrici A., Development of Quantitative Structure-property Relationships Using Calculated Descriptors for the Prediction of the Physicochemical Properties (nD, $\rho, b p, \varepsilon, \eta)$ of a Series of Organic Solvents, J. Chem. Inf. Comput. Sci., 1999, 39, 1190-1203.

[32] Katritzky A.R., Lobanov V.S., Karelson M., QSPR: The Correlation and Quantitative 
Prediction of Chemical and Physical Properties from Structure, Chem. Soc. Rev., 1995, 24, 279-287.

[33] Katritzky A.R., Petrukhin R., Jain R., Karelson M., QSPR Analysis of Flash Points, J. Chem. Inf. Comput. Sci., 2001, 41, 1521-1530.

[34] Katritzky A.R., Stoyanova-Slavova I.B., Dobchev D.A., Karelson M., QSPR Modeling of Flash Points: an Update, J. Mol. Graph. Model., 2007, 26, 529-536.

[35] Keshavarz M.H., Simple Method for Prediction of Activation Energies of the Thermal Decomposition of Nitramines, J. Hazard. Mater., 2009, 162, 1557-1562.

[36] Keshavarz M.H., Pouretedal H.R., Shokrolahi A., Zali A., Semnani A., Predicting Activation Energy of Thermolysis of Polynitroarenes through Molecular Structure, J. Hazard. Mater, 2008, 160, 142-147.

[37] Rice B.M., Hare J.J., A Quantum Mechanical Investigation of the Relation between Impact Sensitivity and the Charge Distribution in Energetic Molecules, J. Phys. Chem. A, 2002, 106, 1770-1783.

[38] Saraf S.R., Rogers W.J., Mannan M.S., Prediction of Reactive Hazards Based on Molecular Structure, J. Hazard. Mater., 2003, 98, 15-29.

[39] Theerlynck E., Mathieu D., Simonetti P., Towards Improved Models to Rationalize and Estimate the Decomposition Temperatures of Nitroalkanes, Nitramines and Nitric Esters, Thermochim. Acta, 2005, 426, 123-129.

[40] Afanas'ev G.T., Pivina T.S., Sukhachev D.V., Comparative Characteristics of Some Experimental and Computational Methods for Estimating Impact Sensitivity Parameters of Explosives, Propellants Explos. Pyrotech., 1993, 18, 309-316.

[41] Toghiani R.K., Toghiani H., Maloney S.W., Boddu V.M., Prediction of Physicochemical Properties of Energetic Materials, Fluid Phase Eq., 2008, 264, 86-92.

[42] Politzer P., Ma Y., Lane P., Concha M.C., Computational Prediction of Standard Gas, Liquid, and Solid-phase Heats of Formation and Heats of Vaporization and Sublimation, Int. J. Quantum. Chem., 2005, 106, 341-347.

[43] Pospisil M., Vavra P., Concha M.C., Murray J.S., Politzer P., A Possible Crystal Volume Factor in the Impact Sensitivities of Some Energetic Compounds, J. Mol. Model., 2010, 16, 895-901.

[44] Meyer R., Köhler J., Homburg A., Explosives, 6th ed., Wiley-VCH, Weinheim, 2007; ISBN 978-3-527-31656-4.

[45] Pagoria P.F., Lee J.S., Mitchell A.R., Schmidt R.D., A Review of Energetic Materials Synthesis, Thermochim. Acta, 2002, 384, 187-204.

[46] Agrawal J.P., Recent Trends in High-energy Materials, Prog. Energy Combust. Sci., 1998, 24, 1-30.

[47] Sikder A.K., Sikder N., A Review of Advanced High Performance, Insensitive and Thermally Stable Energetic Materials Emerging for Military and Space Applications, J. Hazard. Mater. A, 2004, 112, 1-15.

[48] Todeschini R., Consonni V., Pavana M., Milano Chemometrics and QSAR Research Group [Online] available: http://michem.disat.unimib.it/chm/

[49] Leardi R., Boggia R., Terrile M., Genetic Algorithms as a Strategy for Feature 
Selection, J. Chemom., 1992, 6, 267-281.

[50] Agrawal V.K., Khadikar P.V., QSAR Prediction of Toxicity of Nitrobenzenes, Bioorg. Med. Chem., 2001, 9, 3035-3040.

[51] Baumann K., Chance Correlation in Variable Subset Regression: Influence of the Objective Function, the Selection Mechanism, and Ensemble Averaging, QSAR Comb. Sci., 2005, 24, 1033-1046.

[52] Tropsha A., Gramatica P., Gombar V.K., The Importance of Being Earnest: Validation is the Absolute Essential for Successful Application and Interpretation of QSPR Models, QSAR Comb. Sci., 2003, 22, 69-77.

[53] González A.G., Use and Misuse of Supervised Pattern Recognition Methods for Interpreting Compositional Data, J. Chromatogr. A, 2007, 1158, 215-225.

[54] Berrueta L.A., Alonso-Salces R.M., Héberger K., Supervised Pattern Recognition in Food Analysis, J. Chromatogr. A, 2007, 1158, 196-214. 
